\title{
Localisation and temporal variability of groundwater discharge into the Dead Sea using thermal satellite data
}

\author{
U. Mallast $\cdot$ C. Siebert $\cdot$ B. Wagner $\cdot$ \\ M. Sauter $\cdot$ R. Gloaguen $\cdot$ S. Geyer $\cdot$ \\ R. Merz
}

Received: 30 December 2012/ Accepted: 28 February 2013/Published online: 19 March 2013

(C) The Author(s) 2013. This article is published with open access at Springerlink.com

\begin{abstract}
The semi-arid region of the Dead Sea heavily relies on groundwater resources. This dependence is exacerbated by both population growth and agricultural activities and demands a sustainable groundwater management. Yet, information on groundwater discharge as one main component for a sustainable management varies significantly in this area. Moreover, discharge locations, volume and temporal variability are still only partly known. A multi-temporal thermal satellite approach is applied to localise and semi-quantitatively assess groundwater discharge along the entire coastline. The authors use 100 Landsat ETM + band 6.2 data, spanning the years between 2000 and 2011. In the first instance, raw data are transformed to sea surface temperature (SST). To account for groundwater intermittency and to provide a seasonally independent data set $\Delta T$ (maximum SST range) per-pixel within biennial periods is calculated subsequently. Groundwater affected areas (GAA) are characterised by $\Delta T<8.5^{\circ} \mathrm{C}$. Unaffected areas exhibit values $>10^{\circ} \mathrm{C}$. This allows the exact identification of 37 discharge locations
\end{abstract}

Electronic supplementary material The online version of this article (doi:10.1007/s12665-013-2371-6) contains supplementary material, which is available to authorized users.

U. Mallast $(\bowtie) \cdot$ C. Siebert $\cdot$ S. Geyer $\cdot$ R. Merz

Department of Catchment Hydrology, Helmholtz-Centre for Environmental Research (UFZ), 06120 Halle, Germany

e-mail: ulf.mallast@ufz.de

U. Mallast · R. Gloaguen

Remote Sensing Group, Institute of Geology, Freiberg

University of Mining and Technology, 09599 Freiberg, Germany

B. Wagner · M. Sauter

Georg-August-University Göttingen, Applied Geology,

Institute of Geology, 37077 Göttingen, Germany (clusters) along the entire Dead Sea coast, which spatially correspond to available in situ discharge observations. Tracking the GAA extents as a direct indicator of groundwater discharge volume over time reveals (1) a temporal variability correspondence between GAA extents and recharge amounts, (2) the reported rigid ratios of discharge volumes between different spring areas not to be valid for all years considering the total discharge, (3) a certain variability in discharge locations as a consequence of the Dead Sea level drop, and finally (4) the assumed flushing effect of old Dead Sea brines from the sedimentary body to have occurred at least during the two series of 2000-2001 and 2010-2011.

Keywords Landsat ETM+ $\cdot$ Sea surface temperature . Submarine groundwater discharge $\cdot$ Groundwater resource

\section{Introduction}

The water level of the hypersaline Dead Sea (DS) has been decreasing significantly for several decades. Main reasons relate to the high evapotranspiration rates and a decreased groundwater/surface water contribution (Salameh and ElNaser 1999). Primarily, increased anthropogenic water abstraction from groundwater, the main freshwater resource in the region (Feitelson 2005), followed by the Jordan River-the only perennial surface water contribution to the DS have led to the reduction in water level. Although decisive, groundwater quantity is the most difficult to assess (Al-Weshah 2000; Gräbe et al. 2012; Schulz et al. 2013), which has resulted in numerous and discrepant estimates of groundwater discharge into the DS (Table 1).

The significant discrepancies in the estimates can be attributed to the differences in the approaches employed by 
Table 1 Assessments of annual groundwater discharge rates into the DS

\begin{tabular}{|c|c|c|}
\hline Author & $\begin{array}{l}\mathrm{Q} \\
\left(10^{6} \mathrm{~m}^{3} \mathrm{a}^{-1}\right)\end{array}$ & Considered area \\
\hline $\begin{array}{l}\text { Stiller and Chung } \\
(1984)^{\mathrm{c}}\end{array}$ & $>30$ & $\begin{array}{l}\text { Western coast (only some } \\
\text { springs) }\end{array}$ \\
\hline Lensky et al. $(2005)^{\mathrm{b}}$ & 60 & Western and eastern coast \\
\hline $\begin{array}{l}\text { Asmar and Ergenzinger } \\
(2002)^{\mathrm{b}}\end{array}$ & 80 & Western and eastern coast \\
\hline $\begin{array}{l}\text { Laronne Ben-Itzhak and } \\
\text { Gvirtzman }(2005)^{\mathrm{a}}\end{array}$ & 84 & Western coast \\
\hline Salameh $(1996)^{\mathrm{b}}$ & 90 & Eastern coast \\
\hline Guttman $(2000)^{\mathrm{a}}$ & 93 & Western coast \\
\hline $\begin{array}{l}\text { Salameh and El-Naser } \\
(1999)^{\mathrm{b}}\end{array}$ & 140 & Western and eastern coast \\
\hline $\begin{array}{l}\text { Chan and Chung } \\
(1987)^{\mathrm{b}}\end{array}$ & 150 & Western and eastern coast \\
\hline $\begin{array}{l}\text { Israel Hydrological } \\
\text { Service }(2008-2011)^{\mathrm{c}}\end{array}$ & $82-96$ & $\begin{array}{l}\text { Only Ein Feshkha, Kane, } \\
\text { Samar (western coast) }\end{array}$ \\
\hline
\end{tabular}

the various authors. They are either based on water/mass balance calculations or groundwater modelling. Common to all calculations, however, are rigid ratios of discharge volumes between the spring areas (Asmar and Ergenzinger 2002; Laronne Ben-Itzhak and Gvirtzman 2005). In response to the increasing demands on groundwater resources, the Israel Hydrological Service (IHS) initiated a measurement program on the western coast of the DS to monitor discharges from the main spring areas, Ein Feshkha, Kane and Samar either annually or biannually.

While only a fraction (terrestrial springs) of total groundwater discharge to the DS can actually be monitored by direct measurements, data of the main spring area (Ein Feshkha) suggest that the total groundwater discharge rate is decreasing (Galili 2012) accompanied by changes in the groundwater flow-system (Hadas 2011; Magal et al. 2010). Extending the monitoring program along the entire DS coast (ca. $200 \mathrm{~km}$ in 2010) would require extensive transient modelling supported by costly and labour intensive field campaigns.

To reduce the extensive efforts and to parallel gain information on groundwater over large spatial scales in other study areas, some authors applied thermal remote sensing (Danielescu et al. 2009; Johnson et al. 2008; Shaban et al. 2005). This method exploits temperature contrasts between the inflowing groundwater and the water body (river, lake, and ocean). The resulting thermal patterns reveal groundwater discharge locations and their relative importance over large spatial scales. Many studies took advantage of the high spatial resolution with common ground sampling distances (GSD) of $\leq 1 \mathrm{~m}$ provided by airborne platforms to localise and quantify groundwater discharge (Mejías et al. 2012; Roseen 2002; Torgerson et al. 2001). While results are impressive and may lead to an increased knowledge of regional and local hydrogeology in many study areas (Mejías et al. 2012; Shaban et al. 2005), it provides only a snapshot of the discharge event. Moreover, the high-cost of acquiring high resolution thermal data is a distinct disadvantage which in most cases precludes further follow-up campaigns. Especially in (semi-)arid regions where inflow is often intermittent (Becker 2006), multi-temporal data sets are required to obtain a representative reflection of the pattern and spatial extent of groundwater discharge. A multi-temporal approach would additionally facilitate an inter-seasonal comparison of groundwater discharge patterns that can be further analysed in terms of temporal discharge variability.

Although knowledge of the temporal variability of all groundwater inflow is central to understand the dramatic decline of the DS water level and to introduce a sustainable groundwater management, no study to date has addressed the temporal variability of groundwater inflow for the entire Dead Sea.

Hence, the objectives of this study are (1) to identify groundwater inflow locations along the entire DS coast to fill the gap of possible unknown discharge locations and (2) to investigate the spatial and temporal groundwater discharge variability. In this context, we examine the assumed relationship between the temporal discharge behaviour deduced from thermal satellite data with the temporal behaviour of measured spring discharge and recharge along both coasts. The so-obtained temporal and spatial results can subsequently be used to improve existing groundwater models, but may also contribute to sustainable groundwater management decisions in the wider Dead Sea region.

\section{Study area and groundwater flow}

The DS is a terminal lake situated in the Jordan-Dead Sea Graben surrounded by 300-500 $\mathrm{m}$ high escarpments (Fig. 1) formed by normal faults (Gardosh et al. 1990). Due to a left lateral displacement of $105 \mathrm{~km}$ along the Arabian with respect to the African plate boundary, the aquifer bearing strata are different (Ben-Avraham and Ten Brink 1989). Along the western side, the Cretaceous limy Judea Group is identified in most of the sub-catchment area with an upper and a lower subaquifer (U-JGA and L-JGA) separated by the clayey Bet Meir aquiclude (Yechieli et al. 2010; Guttman 2000). On the eastern flank, identified aquifers include the Jurassic Zarqa limestone and Cretaceous Kurnub sandstone aquifers and the overlaying Upper Cretaceous Ajloun- and Belqa Group (Salameh and 
Bannayan 1994). Bounded by the escarpment and along both sides of the DS, a Quaternary coastal aquifer exists. This aquifer comprises intercalated aragonite, gypsum and clay varves that are interlayered with gravel, sand and pebbles at wadi mouths (Gardosh et al. 1990).

Groundwater flow is controlled by the structural geometry, i.e. faults zones and folds with mainly E-W and SWNE orientations along the western side of the DS and W-E and SE-NW orientations on the eastern side (Mallast et al. 2011). The identified control also applies to the coastal aquifer whereby the general flow-direction partly changes as Holocene structural features display ESE-WNW orientations with extensional directions of NNE-SSW (Enzel et al. 2000; Gardosh et al. 1990). Groundwater emerges at distinct locations as a consequence of the structural control. Several authors describe the spring areas of Ein Feshkha, Kane/Samar, Qedem and Ein Gedi (Fig. 1) indicated by terrestrial springs and abundant vegetation along the western coast (Guttman 2000; Laronne Ben-Itzhak and Gvirtzman 2005; Mallast et al. 2011). In contrast (and with the exception of Wadi Zara), vegetation that could indicate shallow groundwater availability directly is not observed along the eastern coast. Nevertheless, Closson et al. (2010) and Akawwi et al. (2008) indirectly demonstrated the occurrence of groundwater discharge via landslide occurrences and airborne thermal remote sensing along the mouths of the Wadis Suweimeh, Zarka Ma'in, Zara and Wadi Mujib, respectively.

Different spring types, which predominantly occur as spring clusters, are common to all discharge locations. Along the western coast, terrestrial springs emerge along faults or sedimentary discontinuities, subsequently forming erosion channels due to the lowering of the DS (Fig. 1b, c). This spring type is included in the afore-mentioned IHS discharge monitoring program since the setting provides favourable measuring sites. The second spring type, submarine springs, is generally located along both coasts and emerges at the lake's bottom. A density difference between emerging groundwater (1.06-1.19 $\mathrm{g} \mathrm{cm}^{-3}$ ) and DS water $\left(1.24 \mathrm{~g} \mathrm{~cm}^{-3}\right)$ triggers buoyancy of the emerging groundwater that surfaces in circular patterns at the DS surface (Munwes et al. 2010) (Fig. 1d). Due to their complex

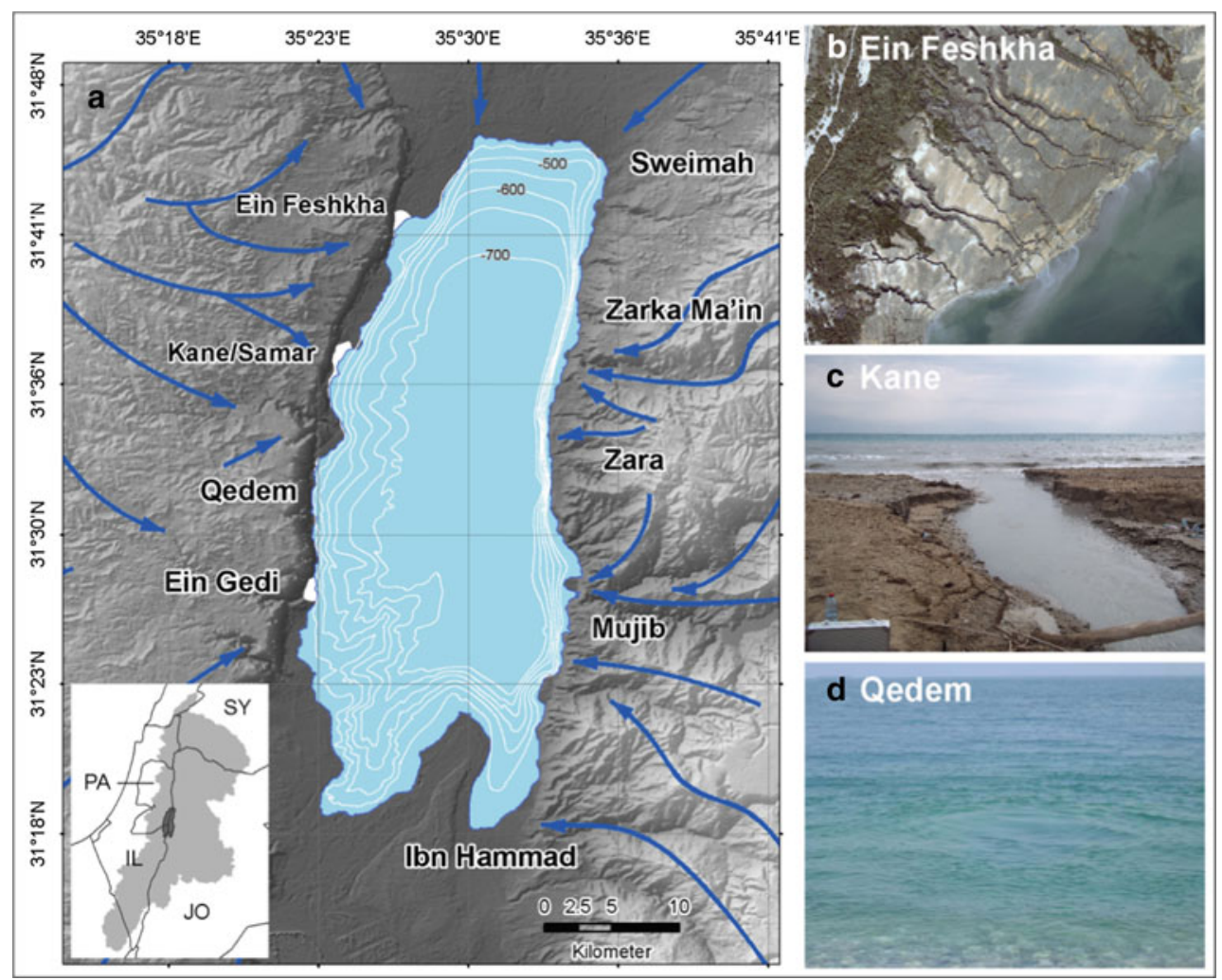

Fig. 1 Study area overview (a blue area represents DS in the year 2000; small white areas represent spring areas (Ein Feshkha,Kane/ Samar, Qedem Ein Gedi); solid blue arrows show general groundwater flow-paths after Mallast et al. 2011; solid white lines indicate $50 \mathrm{~m}$ contour lines of the bathymetry after Hall (2000); Subset: light grey coloured area represents catchment of the DS, dark grey area DS area of the year 2000; IL Israel PA palestine authorities, JO Jordan, SY
Syria); Pictures: all illustrate spring types representative for the study area-b shows an aerial photograph of the northern Ein Feshkha area from 01/2011 with several erosion channels discharging into the DS; c shows a similar erosion channel of an upstream located terrestrial spring in the Kane area and $\mathbf{d}$ shows a submarine spring in the Qedem area (source picture d Munwes et al. 2010) 
nature, their discharges are difficult to quantify and hence not included in the IHS measurements (Ionescu et al. 2012; Munwes et al. 2010).

Spring temperatures vary along both coasts. On the western coast, measured spring discharge temperatures range from $\sim 25-28{ }^{\circ} \mathrm{C}$ (Ein Feshkha), to $\sim 25-30{ }^{\circ} \mathrm{C}$ (Kane), to $\sim 28-30{ }^{\circ} \mathrm{C}$ (Ein Gedi), to $\sim 41-44{ }^{\circ} \mathrm{C}$ (QedemShalem) independent of spring type (Siebert et al. 2011). On the eastern coast, the only direct spring water temperature is reported by Akawwi et al. (2008) with $\sim 24{ }^{\circ} \mathrm{C}$ in the Zara area. Rimawi and Salameh (1988) and Salameh and Hammouri (2008) report further springs from the eastern slope of the Dead Sea with varying temperatures of $22-38{ }^{\circ} \mathrm{C}$ in the Wadi Muijb, Ibn Hammad and Sweimah area and also thermal springs $\left(34-62{ }^{\circ} \mathrm{C}\right)$ in the Zarka Ma' in area. However, it has to be assumed that some of the groundwater feeding the springs, that are not directly located at the DS, discharge into the DS too.

Groundwater temperatures remain rather stable during the course of the year and they are only minimally influenced by ambient air temperature changes (Mallast et al. 2013). In contrast, the general temperature of the DS underlies a clear atmospherical influence resulting in minimum temperatures of $\sim 22{ }^{\circ} \mathrm{C}$ between December and March and maximum temperatures of $\sim 33{ }^{\circ} \mathrm{C}$ between July and September (Hact and Gertman 2003). The thermal contrast between groundwater and DS water approaches a maximum in high summer and winter periods, and hence represent promising periods to identify and analyse groundwater inflow using multi-temporal thermal analyses. This fact is even enhanced by the density difference between fresh to brackish groundwaters $\left(1.06-1.19 \mathrm{~g} \mathrm{~cm}^{-3}\right)$ and lake water $\left(1.24 \mathrm{~g} \mathrm{~cm}^{-3}\right)$. The difference establishes a buoyant layer at the DS surface, in which native groundwater temperatures remain largely unchanged and which further contributes to the suitability of a thermal remote sensing approach for groundwater detection.

Besides groundwater contributions the Dead Sea receives additional fresh water inputs from the Jordan River as perennial flux and ephemeral fluxes from flashfloods through Wadis during the months of November to March. A third, but so far unobserved contribution may exists in the form of the flushing effect (Kiro et al. 2008; Yechieli and Sivan 2011). Rapid drops in the Dead Sea level enforce the hydraulic gradient between groundwater head and lake level and result in an increased groundwater discharge (flushing) until the new dynamic equilibrium is reached (Kiro et al. 2008). This response system causes a significant increase in discharge if the rate of lake level drop and the respective local hydraulic gradient are small. Consequently, a significantly increased groundwater discharge occurs in times in which the DS level drops at an above average rate.

\section{Data and methodology}

Hundred Landsat ETM + band 6.2 (high gain) data (path 174/row 38) covering the years 2000 to 2011 with a cloud cover of less than $15 \%$ are analysed (Appendix 1 in ESM). Although ground sampling distance (GSD) of band 6 is $60 \mathrm{~m}$, all data delivered by the US Geological Survey are resampled to $30 \mathrm{~m}$ using cubic convolution (USGS 2011). Data are recorded at approximately 10 a.m. local time $(\mathrm{GMT}+2)$. First processing steps include a co-registration to UTM WGS 84 Zone $36 \mathrm{~N}$ and a gap fill, since images recorded after the 05/31/2003 contain gaps due to scan line failure of Landsat (USGS 2012). The authors applied the "gap fill" function of Envi 4.7 that is based on a triangulation method with linearly interpolated values between surrounding pixel. Note that the NADIR region with no gaps was located almost parallel and right above the western coast of the DS with a corridor of $\sim 10 \mathrm{~km}$ to each side where subsequently no interpolation is necessary. To exclude land pixels, the normalised difference water index (NDWI) of ETM + band 4 and 2 is calculated from the earliest image of the series. On the resulting NDWI image, a threshold of -0.2 is applied, where values $>-0.2$ represent land features while values $<-0.2$ are explicitly water features (McFeeters 1996). The further processing of data is explicitly elucidated in Mallast et al. (2013) and is subsequently only summarised.

To convert digital numbers (DN) to sea surface temperatures (SST), the authors follow the method presented by Chander et al. (2009). As emissivity value for water, the lower 0.97 value is applied following Wenyao et al. (1987), who proposed this value at higher salinities (>34\%o). Atmospheric transmissivity, upwelling and downwelling radiances needed for the atmospheric correction of the thermal data are obtained through the web-based Atmospheric Correction Tool that is based on MODTRAN (Barsi et al. 2003; Barsi et al. 2005).

The resulting atmospherically corrected SST data represent temperatures with an error of $<1.3 \mathrm{~K}$ for the temperature range of 270-330 K (Barsi et al. 2005). This error applies to the accuracy of SST values during the conversion from DNs with the normal atmosphere thickness, where the sea surface is at mean sea level. The larger atmosphere column for the present case of the DS ( $-400 \mathrm{~m}$ msl.) causes a non-linear reduction of the absolute SST of 2-4 K (Mallast et al. 2013; Stanhill 1990). Note that the temperature represents the skin temperature of the water and, therefore, less than $1 \mathrm{~mm}$ of the uppermost water layer. This layer tends to be ca. $0.1 \mathrm{~K}$ colder than lower water masses due to evaporative heat loss, sensible heat flux and longwave radiation (Wloczyk et al. 2006; Donlon et al. 2002). 
Further data processing included the identification and extraction of images with surface-runoff influence using the influence factor (IF) of Mallast et al. (2013) (see Appendix 2 in ESM for a detailed explanation). This factor describes the difference of normalised mean SST within a radius of $1,000 \mathrm{~m}$ off wadi mouths and the central area of the DS (defined by a $5 \mathrm{~km}$ distance perpendicular to any point of the coastline). If surface-runoff as flash-floods with consistent temperatures below the minimum temperature of the DS occurs, the SST lowers significantly at wadi mouths while the SST of the central area remains uninfluenced. This results in a negative IF where values $\leq-0.053$ indicate an influence through surface-runoff. In a first step, all data below this value are excluded from further groundwater studies. The second step includes the visual reassessment of the images with IF values between -0.053 and 0 as small negative values can be caused by both declining surfacerunoff influence and natural variability (Mallast et al. 2013). The two-step IF analysis allowed the identification of 48 SST images influenced by surface-runoff, but also 51 SST images that are not influenced (Appendix 1 in ESM).

The subsequent multi-temporal analysis to identify groundwater inflows and the inter-seasonal groundwater discharge variability is performed on the not-influenced data as they represent an adequate basis for groundwater investigations.

Within the multi-temporal analysis, two aspects have to be considered to ascertain an optimal analysis. First, the lateral retreat of the DS shoreline amounts to several tens of meters per year in areas with minor sea bed inclination such as at Ein Feshkha. This process possibly causes a relocation of groundwater flow and hence of springs as observed by Magal et al. (2010) and hinders an analysis over the entire investigation period of 2000-2011. Secondly, groundwater flow is intermittent, thus requiring to base the analysis on multiple SST data to assure reliable and most of all representative results (Becker 2006; Mallast et al. 2013). To account for both, minimal effect of the natural retreat of the DS shoreline and a maximum of available SST data, the authors consider biennial series. Each series comprises 5-12 SST images (Fig. 2) on which the maximum temperature range $(\Delta T)$ per-pixel is calculated. $\Delta T$ is defined as the difference between the maximum and minimum SST value. Previous investigations showed this statistical measure to be most suitable to investigate SST variability over time (Mallast et al. 2013). The reason to analyse the temporal SST variability derives from the fact that groundwater discharge affected areas exhibit only a minor SST variability over time. The minor variability derives from a thermal stabilization induced by a spatial and temporal constant groundwater flux that encompasses negligible water temperature variability throughout the year. This continuous groundwater flux that is enhanced by a constant density driven buoyancy establishes a floating layer at the DS surface. As groundwater is permanently supplied, this floating layer gets continuously

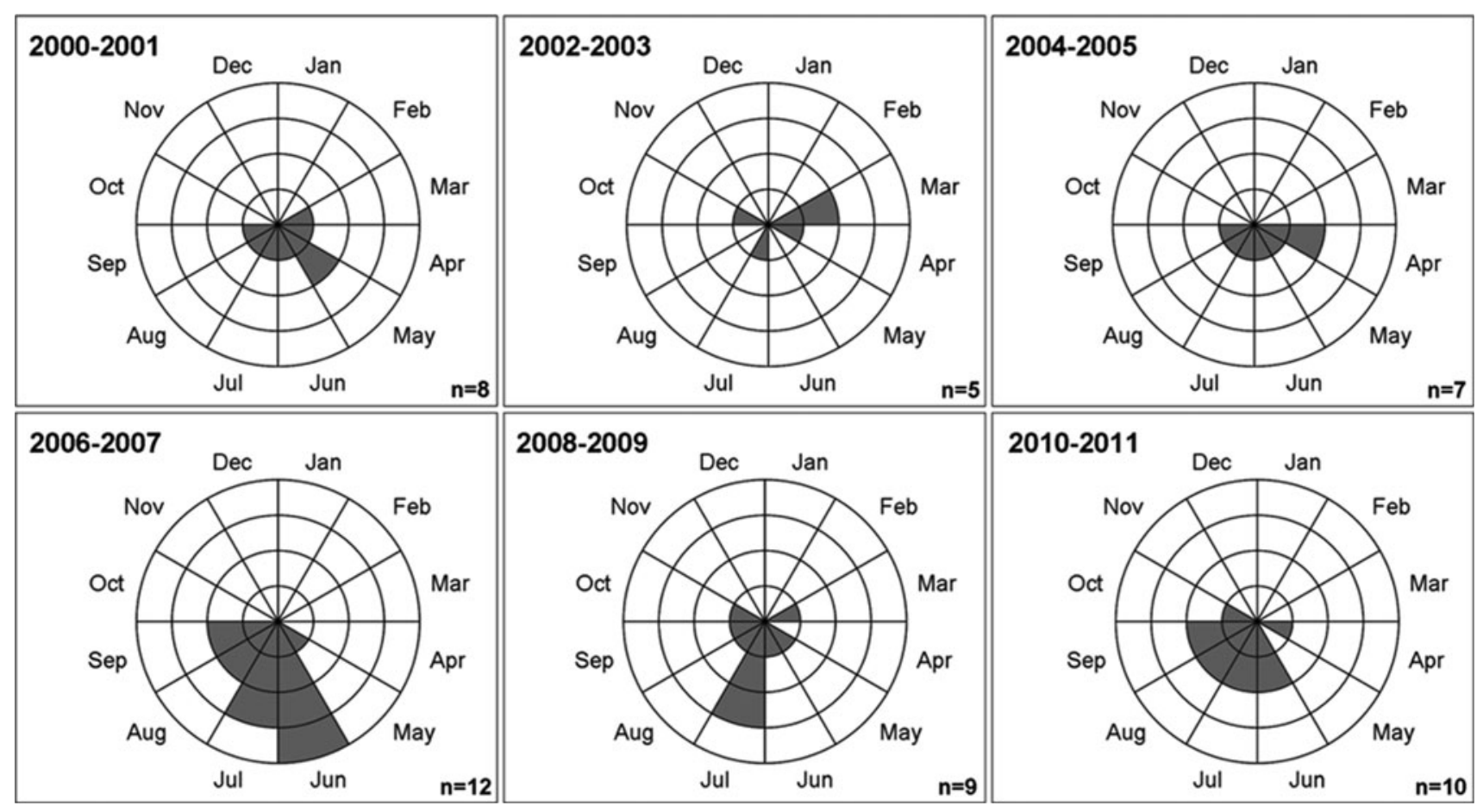

Fig. 2 Temporal distribution of SST recordings (one grey section represents one SST image) and number of SST images (n) compiled to biennial series 
regenerated. At the surface of this layer, the native groundwater temperatures remain largely unchanged and distribute up to tens of meters around the respective spring outlet that in turn can be exploited to identify groundwater discharge locations and temporal discharge variability.

\section{Results and discussion}

Identification of groundwater inflow

The authors focus on areas where groundwater discharge can most likely be expected to investigate the influence of groundwater discharge on the thermal distribution of the DS. Those discharge areas are indicated in a previous study during which Mallast et al. (2011) derived groundwater flow-paths. Extending the flow-paths towards the DS reveals six areas on each coast of the DS (Figs. 3, 4) where proposed flow-paths intersect the shoreline and hence where groundwater inflow occurrence is most likely. As the surface-runoff was excluded during the pre-processing step, all thermal anomalies with low $\Delta T$ values are assumed to reflect groundwater affected areas (GAA). The visually identifiable extent thereby directly mirrors groundwater discharge volume at the respective location (Mallast et al. 2013). The $\Delta T$ value most likely is a measure for the emergence depth, ranging from terrestrial/very shallow to deep spring discharge. Due to the intermittent character of the groundwater discharge and the rather coarse GSD of the SST data, especially small GAAs can visually disappear over different biennial series. To present the most complete result, the authors choose to depict the biennial series, which best reflects the groundwater inflow locations. Additionally, GAAs are classified by continuous coast-parallel extent into: (1) large GAAs ( $>1 \mathrm{~km}$ in length parallel to the coast), (2) small GAAs/single spots $(<1 \mathrm{~km}$

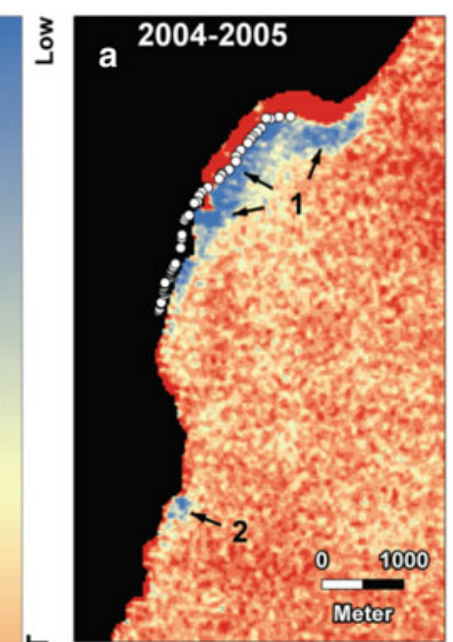

乞
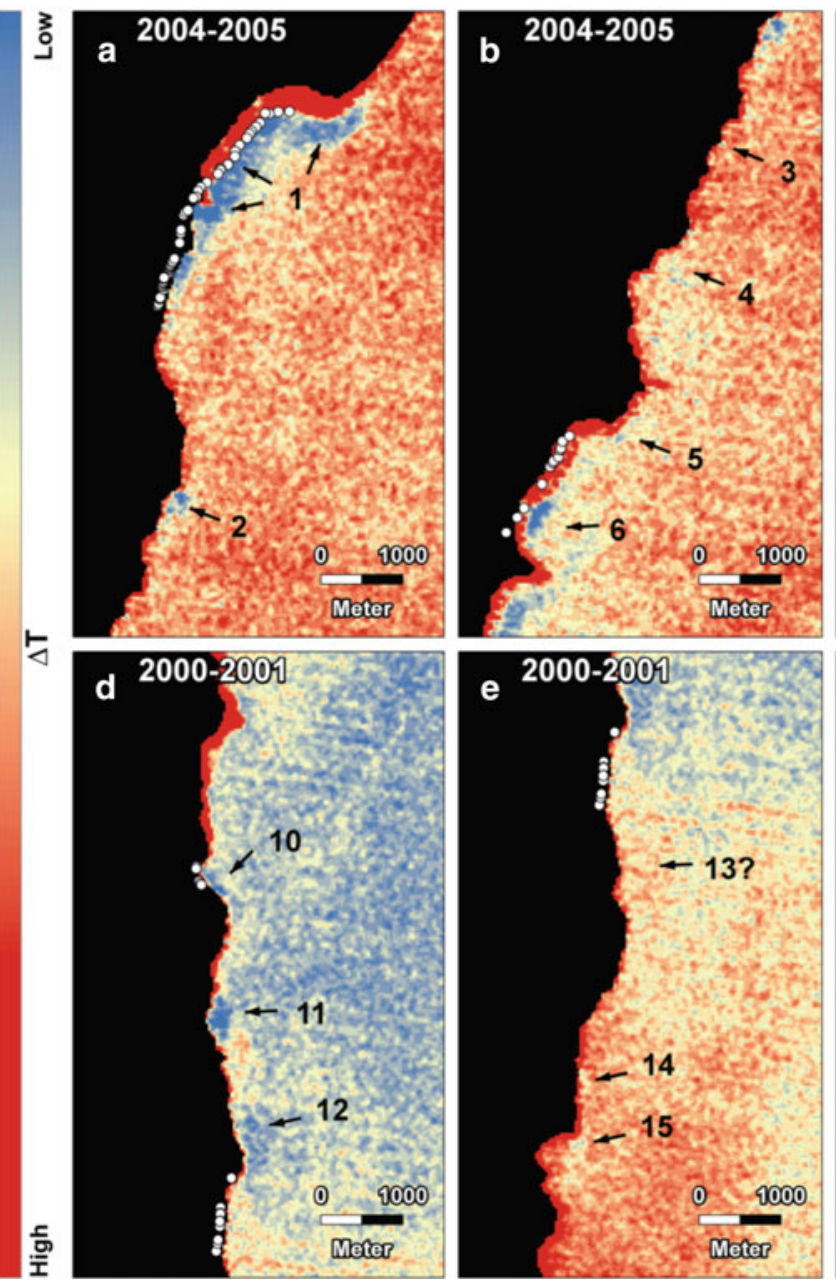

Fig. 3 Identification of inflow locations along the western DS coast-colours indicate $\Delta T$ values per pixel for biennial periods where blue represents small $\Delta T$ values, which indicates stable groundwater inflow while red indicates high $\Delta T$ values caused by
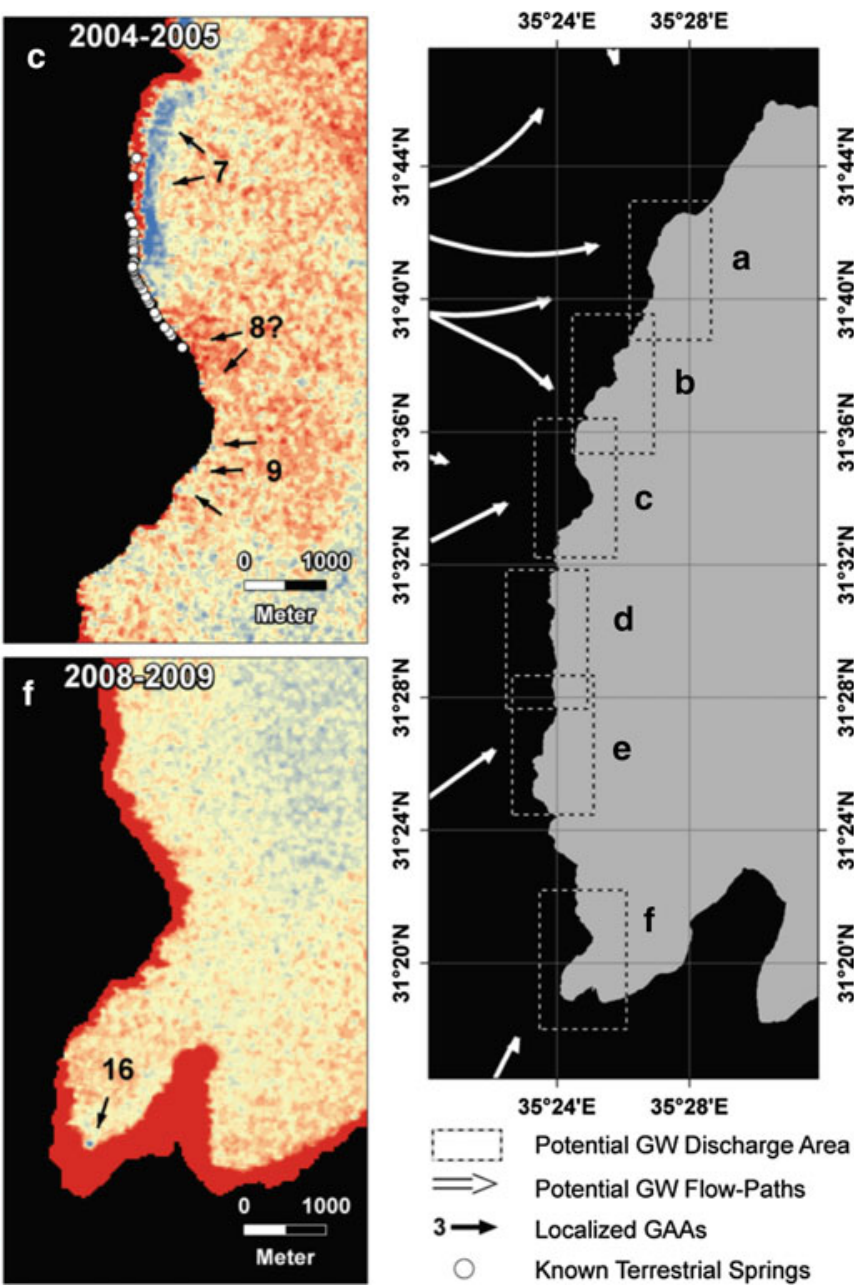

external forces or the retreat of the DS shoreline-letter $\mathbf{a}-\mathbf{f}$ refer to respective discharge areas; the number behind indicates the chosen biennial $\Delta T$ image which shows groundwater inflow best 

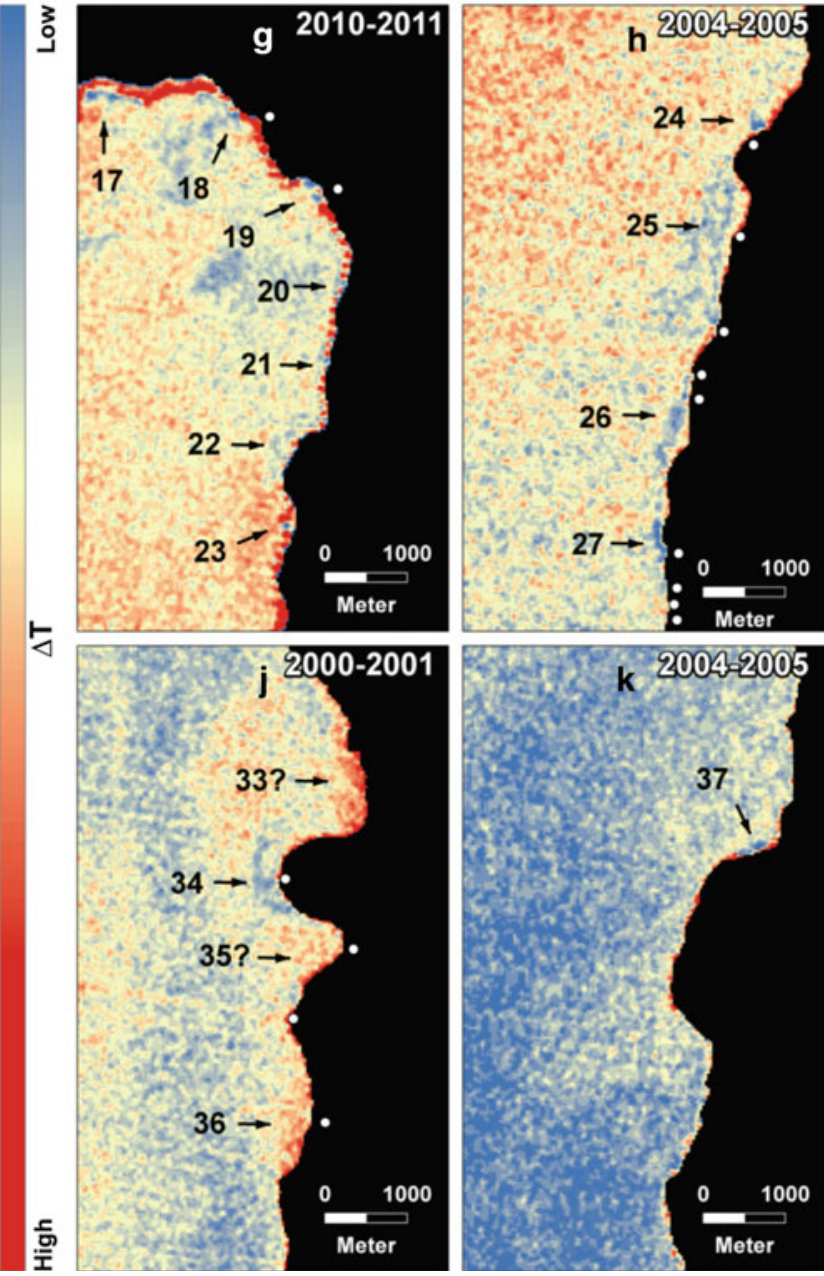

Fig. 4 Identification of groundwater inflow locations along the eastern DS coast-colours indicate $\Delta T$ values per pixel for biennial periods where blue represents small $\Delta T$ values, which indicates stable groundwater inflow while red indicates high $\Delta T$ values caused by

in length parallel to the coast) and (3) assumed/diffuse GAAs to distinguish discharge magnitudes per GAA. All sites with GAAs are subsequently coded with the area where they occur and a running number.

\section{Large GAA}

From the observation of $\Delta T$ data along the entire coast, the authors identify two locations representing large GAAs. Both are located at the western coast of the DS (Fig. 3). The first site (A1), located in discharge area A, exhibits $\Delta T$ values of $6.9-8.5^{\circ} \mathrm{C}$ and a continuous area of $\sim 3.4 \mathrm{~km}$ length parallel to the coast and $\sim 300 \mathrm{~m}$ orthogonal to it. The second site (C7), located in discharge area $\mathrm{C}$, is characterised by small $\Delta T$ values of $6.3-8.5^{\circ} \mathrm{C}$. The extent parallel to the coast is $\sim 2 \mathrm{~km}$ with an orthogonal extent of $\sim 200 \mathrm{~m}$. A1 and C7 correspond to the spring areas of Ein Feshkha and Samar, respectively, which are known to have several terrestrial
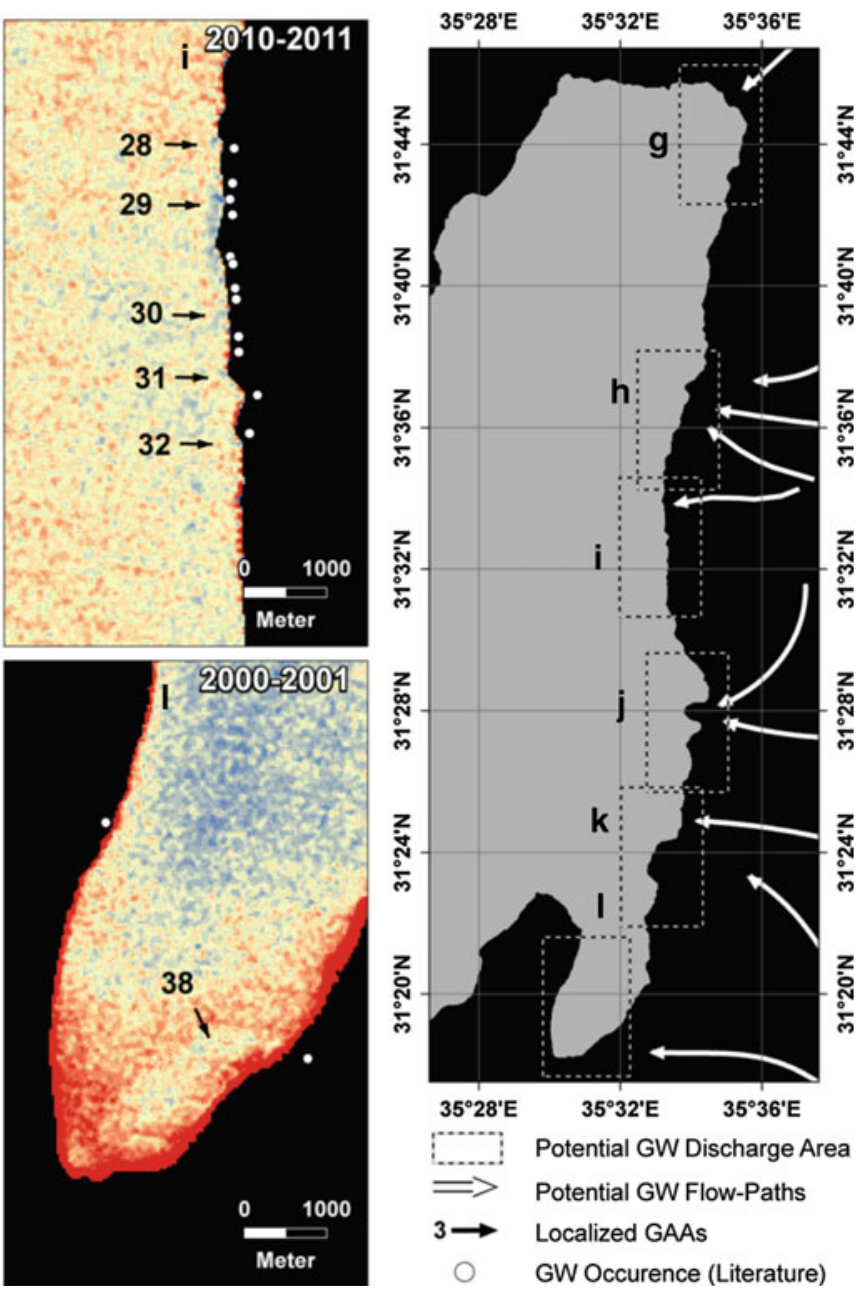

external forces or the retreat of the DS shoreline-letter $\mathbf{g}-\mathbf{l}$ refer to respective discharge area; the number behind indicates the chosen biennial $\Delta T$ image which shows groundwater inflow best

springs (white dots) discharging $82-94 \times 10^{6} \mathrm{~m}^{3} \mathrm{a}^{-1}$ for Ein Feshkha and $19-35 \times 10^{6} \mathrm{~m}^{3} \mathrm{a}^{-1}$ for Samar (note that the numbers originate from the IHS measurements and represent the minimum and maximum numbers between 2004 and 2011) (Guttman 2000; Laronne Ben-Itzhak and Gvirtzman 2005; IHS 2012). The fact that both thermally detected sites spatially correspond to locations of in situ spring measurements distinctively validates thermally inferred groundwater discharge sites. This observation is further supported by similar $\Delta T$ values derived for areas with a stabilised SST through groundwater (Mallast et al. 2013). In fact, as the relationship between in situ groundwater measurements and thermal anomalies appears to be valid, the authors deduce that at both northern ends of site (A1) and (C7) further groundwater discharge occurs. No in situ measurements were conducted at these locations, but $\Delta T$ slightly increases to values $<9.4{ }^{\circ} \mathrm{C}$ over ambient groundwater uninfluenced temperatures $\left(>10^{\circ} \mathrm{C}\right)$. The authors presume that the 
observation of low $\Delta T$ values possibly shows an additional groundwater discharge location of possibly submarine origin.

\section{Small GAA/single spots}

All discharge areas contain small or single spot GAAs with similar $\Delta T$ values of $6.4-8.5^{\circ} \mathrm{C}$ as the afore-mentioned large GAAs on the western coast (Fig. 3). Thermally indicated sites B6, D10 and D11 spatially match in situ measurements of spring discharge (note that B6 corresponds to Kane spring area while D10 and D11 correspond to the Qedem spring area). This verifies the spatial information of inferred thermal anomalies for small GAAs also. The GAA extents (B6 and D11: length $\sim 400 \mathrm{~m} /$ orthogonal extent $\sim 150 \mathrm{~m}$; D10 length $150 \mathrm{~m} /$ orthogonal extent $90 \mathrm{~m}$ ) suggest less discharge compared to the afore-mentioned group and is verified by in situ measurements (B6 6-9 $\times 10^{6} \mathrm{~m}^{3} \mathrm{a}^{-1}$ (IHS 2012 for 2004 to 2005); D11 $10 \times 10^{6} \mathrm{~m}^{3} \mathrm{a}^{-1}$ (Shalev et al. 2007 for 2005); D10 $0.6 \times 10^{6} \mathrm{~m}^{3} \mathrm{a}^{-1}$ (own measurements in 2011). The latter discharge volume reflects only a minimum since several field observations exhibited at least three submarine springs (Fig. 1d) with an estimated sea surface diameter of $\sim 10 \mathrm{~m}$ that probably contribute significantly to the thermally indicated extent of site B6.

Further small GAAs are located at sites A2, B5 E14, E15 and F16. All sites generally exhibit smaller extents except for site A2 that is similar in extent to site D10. Hence, taking site D10 as reference, a similar volume can be assumed for site A2 and that the remaining sites (B5, E14, E15, F16) groundwater discharge is lower by an order of magnitude. On the other hand, the groundwater discharge appears to be mainly of terrestrial/shallow origin, applicable to all of these GAAs, since $\Delta T$ values (8.1-9.0 ${ }^{\circ} \mathrm{C}$ ) are similar to afore-mentioned $\Delta T$ values induced by terrestrial springs.

Despite being noticeable from the $\Delta T$ data, these locations remain unconfirmed as neither terrestrial springs are reported nor could field observations in the years 2010-2011 directly confirm their existence. Sites E14 and E15 could correspond to the Ein Yesha springs that are mentioned in Guttman (2000) and Vengosh et al. (1991). Site F16 seems also reasonable as Shalev et al. (2009) suggest a NE-orientated hydraulic gradient from the Ye'elim area towards the thermally indicated location at the northern DS basin.

On the eastern coast, all discharge areas except for area $\mathrm{F}$ show evidence of small GAAs/single spots. Descriptions of groundwater occurrence from literature are not as exact as on the western coast. This is most likely connected to the steeper coastal morphology and bathymetry which might predominantly result in submarine springs due to the induced increased hydraulic pressure conditions. Closson et al. (2010) and Akawwi et al. (2008) could prove the occurrence of groundwater discharge at some locations that spatially correspond to the thermally indicated small GAAs/ single spots with $\Delta T$ values of $6.3-8.7^{\circ} \mathrm{C}$ at sites G18, G19, H24, I26-27, J28-29, and J34, respectively (see white dots in Fig. 4). The spatial extents of site H24 (160 m parallel and $70 \mathrm{~m}$ orthogonal to the coast, respectively) are similar to site D10 on the western coast and thus a discharge volume of similar magnitude $\left(>0.6 \times 10^{6} \mathrm{~m}^{3} \mathrm{a}^{-1}\right)$ is assumable. The two low $\Delta T$ value spots at site G19 have slightly smaller extents (100 m parallel and $70 \mathrm{~m}$ orthogonal to the coast). Consequently, the discharge volume appears to be slightly smaller than for site H24. Site H27 on the other hand has a spatial extent of $300 \mathrm{~m}$ parallel and $120 \mathrm{~m}$ orthogonal to the coast indicating a higher discharge volume. All three mentioned GAAs (G19, H24, H27) are characterised by $\Delta T$ values of $6.9-8.7^{\circ} \mathrm{C}$ and a direct connection to the coast. Both aspects commend to a shallow or terrestrial emergence that applies for sites G18, I28 and at least the northern end of site I29 also. Most parts of sites I29 and $\mathrm{J} 34$ display similar $\Delta T$ values $\left(7.5-8.4{ }^{\circ} \mathrm{C}\right)$ but do not have a direct connection to the coast, which suggests a deeper submarine emergence. For these locations, it is difficult to approximate discharge magnitudes, since neither the required thermodynamic mechanisms and parameters nor the exact emergence depth are known.

Beside the GAAs that spatially correspond to reported groundwater occurrences, sites G20, G21, G23 and K37 reflect thermal anomalies with $\Delta T$ values of $6.9-8.5{ }^{\circ} \mathrm{C}$ that point at continuous groundwater discharge. Yet these sites are not mentioned in literature. The near-shore location suggests these sites to have a shallow/terrestrial emergence. Site G23 represents an exception since it has no direct connection to the coast and is probably of submarine origin. However, the extents differ considerably. Whereas sites G20, G21 and G23 display small spatial extents with $<100 \mathrm{~m}$ parallel and $<60 \mathrm{~m}$ orthogonal to the coast and hence a small discharge magnitude, site K37 has a similar extent (parallel to the coast $150 \mathrm{~m}$ and orthogonal to it $90 \mathrm{~m}$ ). This extent is comparable to site G19 why the authors assume a similar magnitude of discharge also. The authors furthermore suggest that all of these GAAs reflect groundwater discharge. Nonetheless, these GAAs are unconfirmed due to missing ground information.

Moreover, it should be mentioned that site G17, which falls into the group of small GAA, probably does not reflect a GAA. Instead, it represents discharge from the Jordan River as the coordinates correspond to the location of its mouth.

\section{Assumed/diffuse GAAs}

This class contains all GAAs that cannot clearly be distinguished based on homogenous small $\Delta T$ values and yet 
display certain peculiarities noteworthy to mention. Based on these peculiarities they can be allocated into three groups.

The first group contains hardly visible GAAs. Sites B3, B4 and C9 are located on the western coast and I30-32 on the eastern coast. All GAAs of this group on the western coast are characterised by extents $<4$ pixel (pixel size: $30 \times 30 \mathrm{~m}$ ) and $\Delta T$ values of $8.9-9.5^{\circ} \mathrm{C}$ emphasised by high ambient $\Delta T$ values $\left(>10^{\circ} \mathrm{C}\right)$. The slightly higher $\Delta T$ values might indicate low groundwater discharge. The small contrast to ambient SST represents an unfavourable condition. Thus, the authors suggest these sites to be allocated to "assumed GAAs" requiring further groundtruth data. This is in contrast to the GAAs on the eastern coast (sites I30-32). Here, GAAs are also characterised by similar $\Delta T$ values of $8.1-9.2^{\circ} \mathrm{C}$, exhibiting, however, larger connected extents ( $>6$ pixel). Additionally, all of these sites are verified by already confirmed groundwater discharge locations (Akawwi et al. 2008). Hence, the authors suggest the eastern GAAs of this group to truly reflect groundwater discharge. The emergence is probably submarine with very low discharge magnitudes causing $\Delta T$ values of $8.5-9.5^{\circ} \mathrm{C}$.

The second group comprises heterogeneous GAAs with large extents (1-2 km parallel and $\sim 500 \mathrm{~m}$ orthogonal to the coast, respectively). Site D12 on the western coast and sites $\mathrm{G} 22, \mathrm{H} 25$, and F38 on the eastern coast belong to this group. Akawwi et al. (2008) report a submarine groundwater inflow for site $\mathrm{H} 25$ that verifies our finding. The same applies to site F38, where extensive studies of Closson (2005) and Closson et al. (2010) report landslides, subsidence and sinkhole occurrences that directly or indirectly depend on shallow groundwater flow and dynamics. Both verifications indicate these GAAs to have a groundwater origin. The question remains why these GAAs display slightly increased and heterogeneous $\Delta T$ values $\left(8.2-8.9^{\circ} \mathrm{C}\right)$. The missing direct connection to the shore of all (except for site G22) indicates a submarine origin. At all locations (except for site F38), the bathymetry is unequally steep. These GAAs are located at the $-450 \mathrm{~m}$ msl. isoline on both coasts (Fig. 1), which means a water depth of around $<35 \mathrm{~m}$ (taking the DS level of $-415 \mathrm{~m} \mathrm{msl}$. of 2001 and $-417 \mathrm{~m} \mathrm{msl}$. of 2005). Ionescu et al. (2012) describe the occurrence of submarine springs up to a depth of $\sim 30 \mathrm{~m}$. Hence, from a hydrostatical perspective, this observation indicates these GAAs to be generally reasonable. The slightly higher $\Delta T$ values that characterise this group could have two origins. First, as the groundwater ascents due to different densities, a heat exchange between the DS water and the discharging and ascending groundwater occurs. This partly changes the original temperature of the groundwater to the DS water. Most of the $\Delta T$ data are recorded in summer months, during which the DS has a temperature of $32-35^{\circ} \mathrm{C}$. The resulting $\Delta T$ between DS water and groundwater amounts to $4-7{ }^{\circ} \mathrm{C}$. The density driven buoyancy of the groundwater yields a velocity of $\sim 0.4 \mathrm{~m} \mathrm{~s}^{-1}$ and hence a travelling time of $\sim 75 \mathrm{~s}$ for emerging water at a depth of $30 \mathrm{~m}$ (deepest observed submarine spring) (Ionescu et al. 2012; Mallast et al. 2013). Complete temperature equilibrium within the short travelling time is, therefore, unlikely. A certain temperature adaption, however, can be assumed.

Second and probably more decisive is the influence of different limno-physical mechanisms (e.g. currents, temperature diffusion, etc.) on the ascending groundwater. These mechanisms might influence the vertical flow causing the circular pattern at the sea surface to move in horizontal dimensions by some meters over a longer time period. The movement could be repeatedly observed in the field and may explain why springs with submarine origin are thermally unequally clearly visible on the sea surface compared to groundwater that discharges in shallow areas.

The third group encompasses GAAs that are characterised by a near-shore cluster of high $\Delta T$ with values of 10.5-12.2 ${ }^{\circ} \mathrm{C}$, which differ from ambient SSTs. This is in contrast to the aforementioned analysed characteristic that steady groundwater discharge with large discharge volume stabilizes ambient SSTs that subsequently cause low $\Delta T$ values.

However, several of these GAAs are observed at both coasts (sites C8, E13, J33, J35 and J36) that match independent groundwater discharge observations and in situ measurement locations (Figs. 3, 4). It is known from the IHS measurements in 11/2004 that at the location of site C8 several springs exist with minor discharge volumes of $<0.015 \times 10^{6} \mathrm{~m}^{3} \mathrm{a}^{-1}$, while only two springs exhibit discharge volumes of $0.3-0.5 \times 10^{6} \mathrm{~m}^{3} \mathrm{a}^{-1}$, respectively. Due to these very small discharge volumes that are distributed along a shore strip of $>1 \mathrm{~km}$ and mostly along coarse grained wadi fans the authors hypothesise that these rather diffusely discharging springs with low flow dynamics (Fig. 5) and quantity stabilize only a small fringe along the DS coast. This fringe cannot be resolved by the coarse GSD of the SST data. In periods with increased discharge, due to, e.g. the flushing effect, the thermally stabilised area increases and is captured by the SST data subsequently, despite the coarse GSD. As a consequence, the alternation of both discharge situations could lead to higher observed $\Delta T$ values.

Akawwi et al. (2008) reported groundwater discharge locations for two of the GAAs on the eastern coast (sites J35 and J36) that validate our findings. Hence, the authors suggest that this thermal pattern potentially indicates groundwater discharge, with mostly diffuse emergence and small discharge magnitudes. 
Fig. 5 Observed groundwater inflow at the tip (a) and a northern section (b) of the Wadi Darga fan (GAA site C8/Samar spring area)
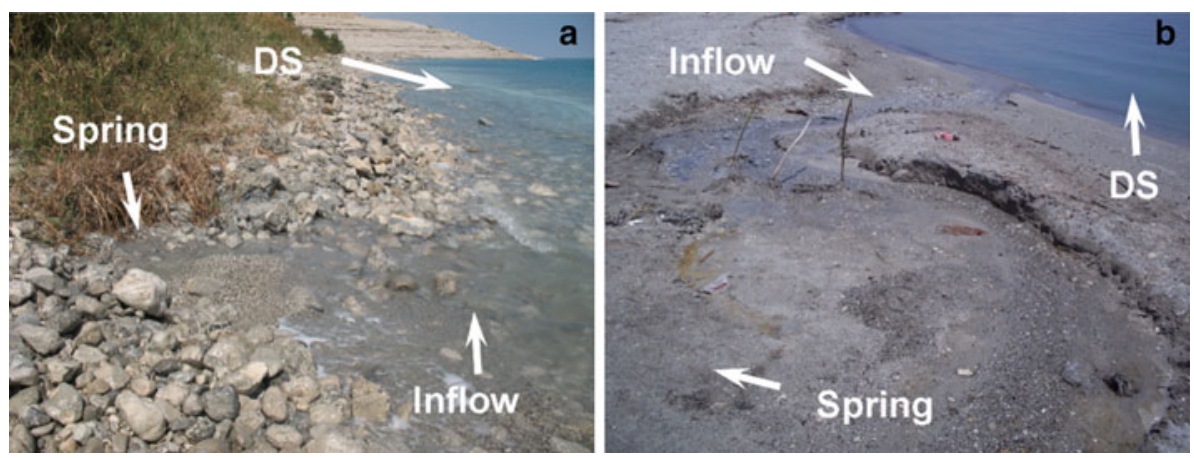

Hence, on the positive side the authors conclude that

(i) All discharge areas (A-L) indicated through previously inferred groundwater flow-paths exhibit GAAs.

(ii) 37 exact locations could be identified, where groundwater discharge occurs along both coasts.

(iii) The findings spatially match available in situ measurement locations or ground observations.

(iv) 15 concrete indications for spring locations could be provided where so far groundwater discharge was unknown to occur.

(v) GAA extents and location with respect to the coast and $\Delta T$ values provide an indication of discharge magnitude and probable origin.

Also noticeable are 8 IHS measurement locations between sites B5, B6 and 8 own spring measurements in 2011 south of site E12, where neither low nor distinctive high $\Delta T$ values at the same longitude are present. Most of these show discharge volumes of $0.02-0.18 \times 10^{6} \mathrm{~m}^{3} \mathrm{a}^{-1}$. Only two springs in discharge area $\mathrm{B}$ and two in discharge area E exhibit values of $0.23-0.41 \times 10^{6} \mathrm{~m}^{3} \mathrm{a}^{-1}$. From this fact, the authors would argue that the applied thermal analysis based on coarse GSD satellite data has a clear limitation if it comes to the identification of discharge volumes with a magnitude of $<0.4 \times 10^{6} \mathrm{~m}^{3} \mathrm{a}^{-1}$. If the intention is to identify all groundwater inflow independent of quantity, the authors suggest using airborne thermal imaging as it is applied in the study of Akawwi et al. (2008). For the detection of larger discharge volumes, the applied multi-temporal thermal satellite data prove a successful applicability.

Inter-biennial groundwater discharge variability

With the exact spring locations identified, the temporal discharge variability is being analysed for the years 2000 to 2011. Due to the variability in discharge volume, some discharge areas display no visually delimitable GAAs. Hence, the focus is set on GAAs that are continuously distinguishable throughout the entire investigation period. These GAAs are located in discharge areas A-C on the western coast and $\mathrm{H}$ and $\mathrm{J}$ on the eastern coast.
The SST data included in all series are recorded between March and October (Fig. 2). Hence, the results reflect the same hydrological time of the year and imply comparability between biennial series. Within each series, the $\Delta T$ values are Gaussian distributed where the groundwater caused lower $\Delta T$ values display below the 95 percentile of the normalised $\Delta T$. This threshold and the constraint for the GAAs to have a minimum Euclidian distance of $120 \mathrm{~m} \mathrm{(4}$ pixels) to the coast are taken to delineate the GAAs in the respective series. Both parameters allow the determination of the temporal evolution of groundwater discharge quantitatively in which GAA extents are proportional related to groundwater discharge volume.

\section{Western coast}

The GAA extent and hence the groundwater discharge derived from the $\Delta T$ data indicate a significant but unsteady decrease in all discharge areas during the observation span (Fig. 6). For discharge area A, which corresponds to the spring area of Ein Feshkha, the behaviour of the GAA extents exhibits a three-steps change. From 2000 to 2001 to 2002 to 2003, the GAA decreases from 2.41 to $0.68 \mathrm{~km}^{2}$. It then remains constant for the subsequent 2004-2005 series $\left(0.69 \mathrm{~km}^{2}\right)$. The following two series again show a significant decrease to $>0.14 \mathrm{~km}^{2}$ before the GAA increases to $0.83 \mathrm{~km}^{2}$ during 2010-2011 (Fig. 6). For the years 2004-2011, IHS spring measurements show an identical but less pronounced behaviour except for the last increase that will be discussed later. Mean total measured groundwater discharge decreases almost linearly from $71.0 \times 10^{6} \mathrm{~m}^{3} \mathrm{a}^{-1}$ during 2004-2005 to $60.2 \times 10^{6} \mathrm{~m}^{3} \mathrm{a}^{-1}$ during 2008-2009 series (Fig. 6).

Discharge area B/C (lower row in Fig. 6) shows a different behaviour. The changeover from 2000-2001 to 2002-2003 demonstrates a similar GAA decrease from 3.24 to $0.08 \mathrm{~km}^{2}$ as in discharge area A (Fig. 6). The following series (2004-2005) unlike discharge area A exhibits an increase to $0.42 \mathrm{~km}^{2}$. This surface remains stable during 2006-2007, but unlike discharge area A, it decreases to $0.05 \mathrm{~km}^{2}$ until the 2008-2009 series. The last changeover to 


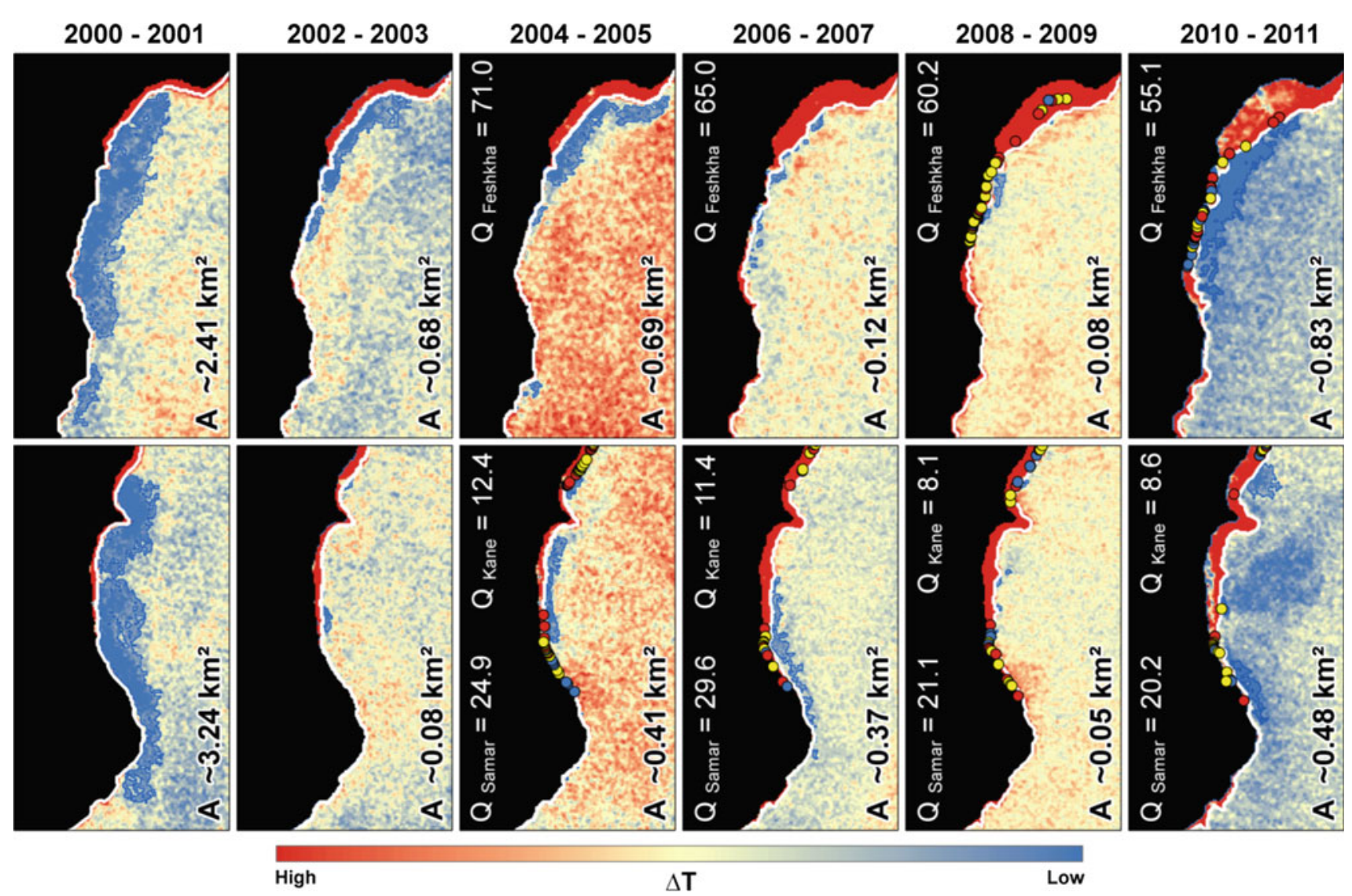

Fig. 6 Temporal variability of discharge behaviour per biennial series between 2000 and 2011 at the example of identified areas A and B/C. $\Delta T$ values per pixel of the SST data in the respective series shown are with bluecolours indicating low $\Delta T$ values and hence GAA and red colours indicating high $\Delta T$ values with highly variable temperatures and no groundwater influence. Numbers in the lower right corner represent the total area of the GAA while the numbers in

the 2010-2011 series behaves similarly as it exhibits an increase. Comparing the total GAA to the IHS spring measurements reveals an analogous behaviour. The mean total spring discharge $\left(Q_{\text {Kane }}\right.$ and $Q_{\text {Feshkha }}$ accumulated) of $37.6 \times 10^{6} \mathrm{~m}^{3} \mathrm{a}^{-1}$ during 2004-2005 is similar to $41.1 \times 10^{6} \mathrm{~m}^{3} \mathrm{a}^{-1}$ during the 2006-2007 series, before it decreases to $30.4 \times 10^{6} \mathrm{~m}^{3} \mathrm{a}^{-1}$ during 2008-2009 (Fig. 6). These numbers suggest that if one takes the IHS measured terrestrial spring discharge into account only the always reported rigid discharge ratio of 2:1 between Ein Feshkha (discharge area $\mathrm{A}$ ) and Kane/Samar (discharge area $\mathrm{B} / \mathrm{C}$ ) is true. In contrast, our results that also include submarine springs suggest that the discharge ratio between both areas can vary inter-annually between 8:1 and 1:3 (Fig. 6).

There is a further interesting observation next to the variation in groundwater discharge rates. Our temporal comparison suggests variable groundwater discharge locations across time. In discharge area $\mathrm{A}$, for example, an inflow is apparent along the entire bay structure during the upper left corner represent IHS mean measured spring discharge in the respective series. Red, Yellow and blue dots represent IHS measured spring discharge of $\leq 0.1 \times 10^{6} \mathrm{~m}^{3} \mathrm{a}^{-1}$ (blue), $>0.1-$ $\leq 1.0 \times 10^{6} \mathrm{~m}^{3} \mathrm{a}^{-1}$ (yellow) and $>1.0 \times 10^{6} \mathrm{~m}^{3} \mathrm{a}^{-1}$ (red). Note that the white solid line represents the coast line of the last image of the series

2000-2001 (Fig. 6). During the following two series inflow only occurs along the northern and central part of the bay. Emergence gradually starts to disappear from the north over the subsequent two series leaving only inflow locations at the bay centre. Magal et al. (2010) report similar findings and describe the gradual drying out of northern springs at the Ein Feshkha Nature Reserve. In contrast, during the last series (2010-2011) the springs seem to reappear along the entire bay. The same phenomenon takes place in discharge area $\mathrm{B} / \mathrm{C}$ where a shift of groundwater inflow locations from north to south is visible between 2004 and 2007. The dis- and reappearance of springs along this strip of discharge area $\mathrm{B} / \mathrm{C}$ was also observed during several field observations during the years 2009-2011, which supports the results obtained from the multi-temporal thermal analysis.

The authors hypothesise that this change is not only a result of different recharge amounts and areas. It might additionally indicate the formation of new preferential 
flow-paths triggered by the lowering of the DS and the location of narrow fault- and folding zones described by Enzel et al. (2000). Groundwater potentials adjust to the dropping of the DS level. This could lead to the activation of a lower lying fault zone as preferential flow-path, which could slightly differ in orientation than overlying fault zones. Or, the internal folding of this zone governs the flow-direction and hence the discharge location.

The fact that the 2000-2001 and 2010-2011 series differ in appearance from the remaining series 2002-2003 until 2008-2009 is also striking. While $\Delta T$ data of the latter series show distinct discharge points that mostly correspond to high quantity spring discharge (see red points in Fig. 6), the 2000-2001 and 2010-2011 series show a spatially continuous discharge over large areas. This phenomenon is probably due to the flushing effect (Kiro et al. 2008) that will be discussed later.

Plotting the GAA of the respective series against the calculated recharge (Fig. 7) using the empirical formula given in Guttman (2000) (Appendix 3 in ESM) reveals a similar curve progression with a delayed response time of one series. This similarity is supported by high index of agreement $(d)$ values (index varies between 0 and 1 , where
1 indicates a perfect fit of curve progression and 0 indicates no fit (Willmott 1981)) of $d=0.71$ for Ein Feshkha and $d=0.66$ for Kane/Samar (Appendix 4 in ESM). Recharge curve and spring discharge from IHS measurements for Kane/Samar also display a conform behaviour. In contrast, the recorded Ein Feshkha groundwater discharge rate shows an almost linear decrease and hence a non-conform behaviour with respect to the average biennial recharge. This might indicate a different hydrological system with multiple input sources than only recharge from the Judean mountains.

The GAA curve and recharge curve are dissimilar during 2000-2001 and 2010-2011. It is striking that concurrently, the lake level drops at a maximum of $1.5 \mathrm{~m}$ and $1.6 \mathrm{~m}$ during these series. Both numbers are above the long-term average drop of $1 \mathrm{~m}$. For this situation with above average drops of the lake level, Kiro et al. (2008) and Yechieli and Sivan (2011) propose an increased discharge due to the contribution of old brines (flushing effect) that could explain the larger GAAs.

Hence, the authors hypothesise that the larger GAAs during both periods are a consequence of the so far unobserved flushing effect. The flushing of old brines is
Fig. 7 Comparison of GAA per identified areas A (equivalent to Ein Feshkha) and B/C (equivalent to Kane/Samar) against the mean recharge amount calculated using rainfall information $\left[\mathrm{mm} \mathrm{a}^{-1}\right]$ of Jerusalem station and the empirical equation from Guttman (2000) and the mean, maximum and minimum DS level drop per series

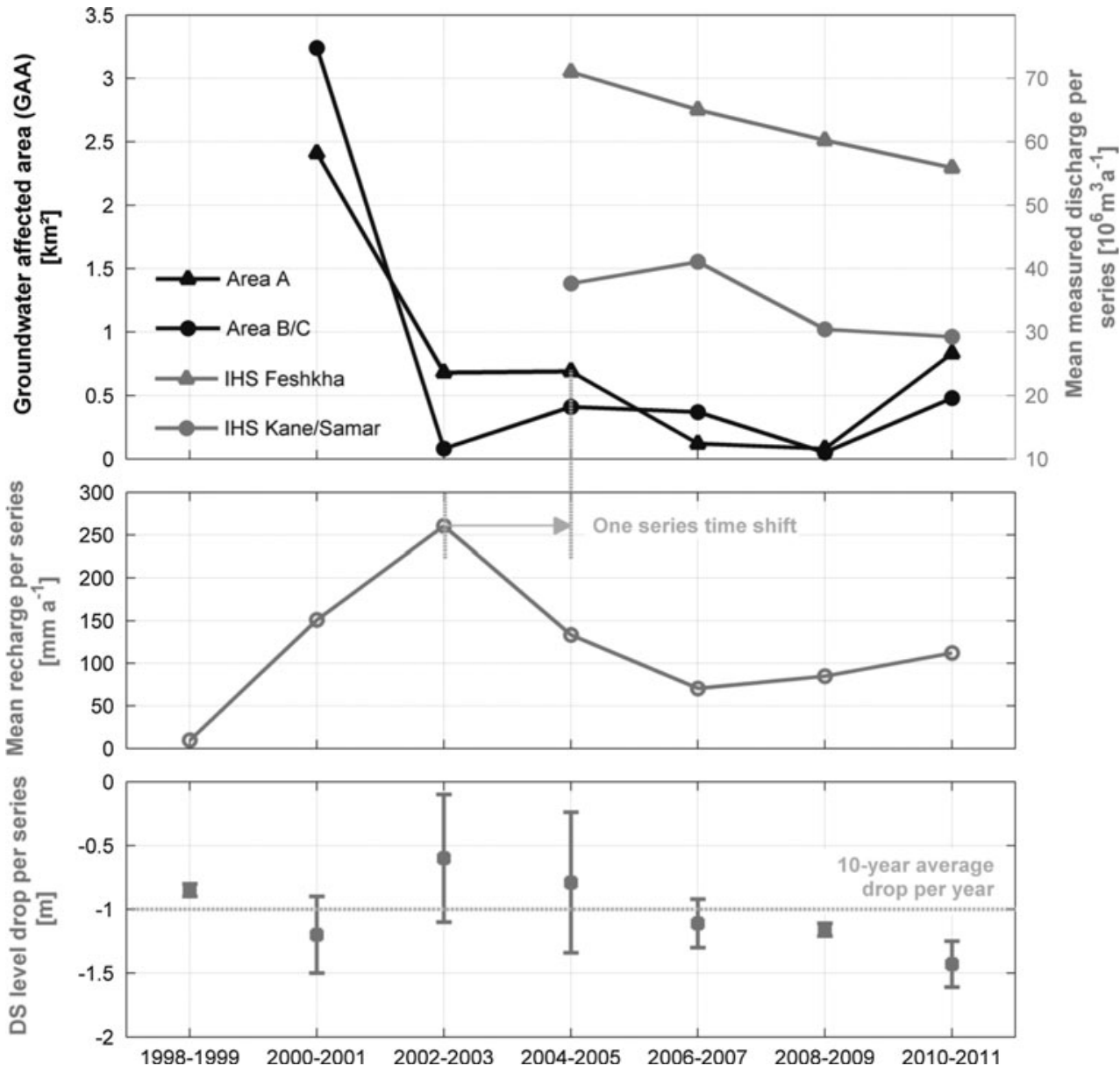




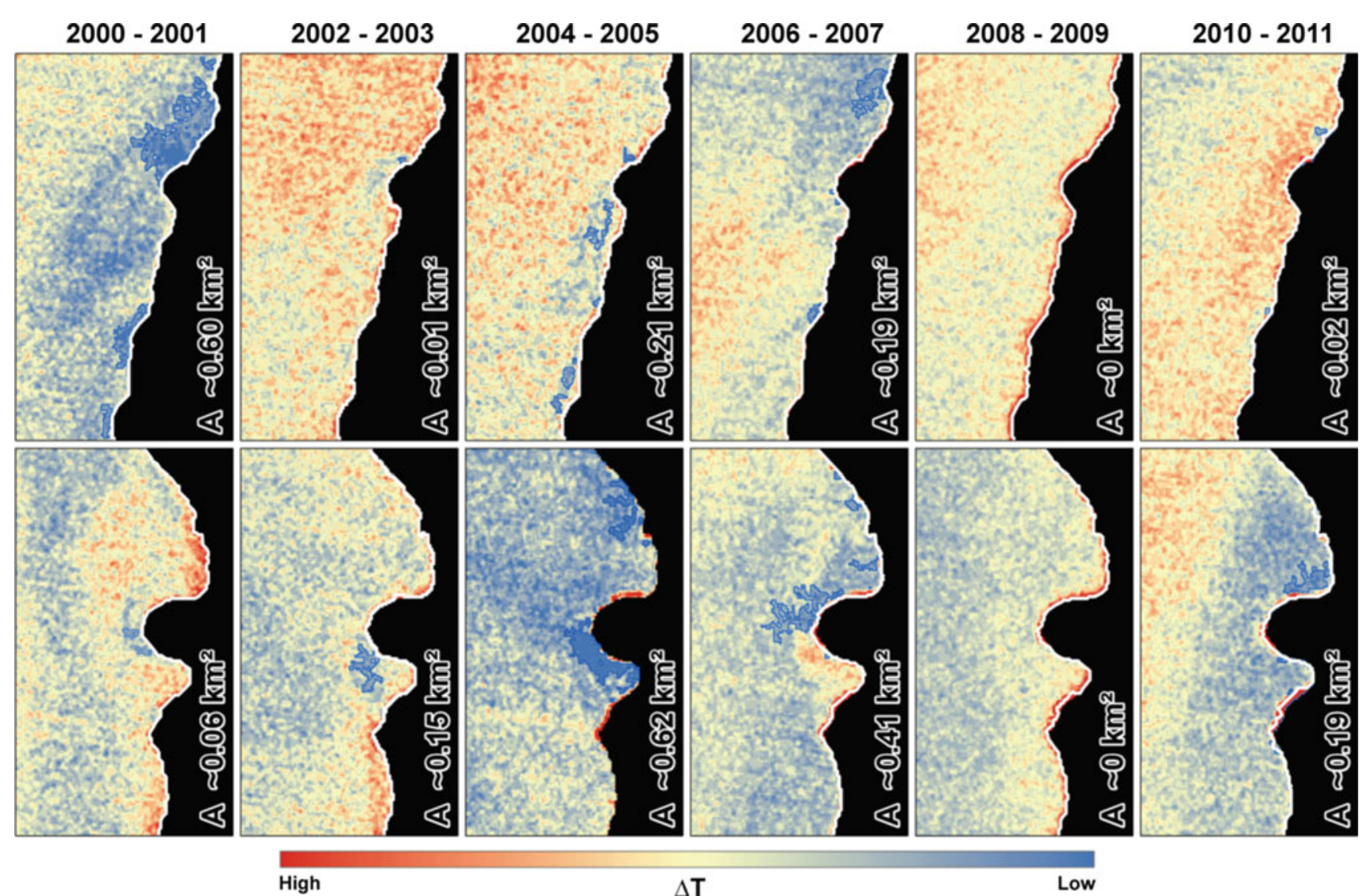

Fig. 8 Temporal variability of discharge behaviour per biennial series between 2000 and 2011 demonstrated on areas $\mathrm{H}$ and $\mathrm{J}$. $\Delta T$ values per pixel of the SST data of the respective series are shown with blue colours indicating low $\Delta T$ values and hence GAA and red

connected to the availability of void spaces to temporarily store water. With the recently exposed Quaternary unconsolidated sandy and clayey lake sediment areas along the entire coastline, this possibility is given and in turn induces an increased discharge over large areas rather than at discrete points. Observations based on the thermal GAA indications show that both discharge areas $\mathrm{A}$ and $\mathrm{B} / \mathrm{C}$ exhibit theses assumed continuous discharge appearance. This supports the hypothesis of an occurring partial flushing mainly during the 2000-2001 and 2010-2011 series.

\section{Eastern coast}

Unlike at the western coast, the discharge areas $\mathrm{H}$ (Wadi Zarka Ma'in and Zara) and J (Wadi Mujib) along the eastern coast do not display a homogeneously decreasing trend. Instead, area $\mathrm{H}$ (upper row in Fig. 8) shows a sinusoidal course of decreasing and increasing GAA, whereas the GAA in area $\mathbf{J}$ (lower row Fig. 8) increases until 2004-2005 and decreases from thereon. Striking is the GAA in discharge area $\mathrm{H}$ in the $2000-2001$ series that is with $0.6 \mathrm{~km}^{2}$ significantly higher than GAAs of the subsequent series. The same colours indicating high $\Delta T$ values with highly variable SSTs and no groundwater influence. Numbers in the lower right corner represent the total area of the GAA. Note that the white solid line represents the coast line of the last image of the series

series provides an indication that the flushing effect of old brines occurs on the eastern coast also. The reason is the continuous appearance of GAAs in contrast to remaining series with rather distinctive discharge locations analogously to the discharge areas $\mathrm{A}$ and $\mathrm{B} / \mathrm{C}$ on the western coast during the same 2000-2001 series.

In discharge area $\mathrm{J}$, higher $\Delta T$ values can be observed along the entire coastline. As this observation indicates diffuse discharge with minor volumes (see Sect. 4) and as it occurs over a continuous spatial extent along the coast, the authors assume this pattern to be caused by the flushing effect. The topography may be responsible for the low discharge quantities. Unlike the western coast, the eastern coast exhibits steep slopes that extend offshore, with generally non-existent or less developed Quaternary lake sediments (Closson et al. 2010). This, in turn, means less void spaces compared to the western coast, and hence lower quantities of groundwater which are temporarily stored and available for flushing from unconsolidated sediments.

Plotting the derived GAA against the calculated recharge depth (Fig. 9) with the empirical formula given in Guttman (2000) (Appendix 3 in ESM) reveals a similar curve 
Fig. 9 Comparison of GAA per identified areas $\mathrm{H}$ and $\mathrm{J}$ against the mean recharge amount calculated using rainfall information $\left[\mathrm{mm} \mathrm{a}^{-1}\right]$ of Amman station and the empirical equation from Guttman (2000) and the mean, maximum and minimum DS level drop per series
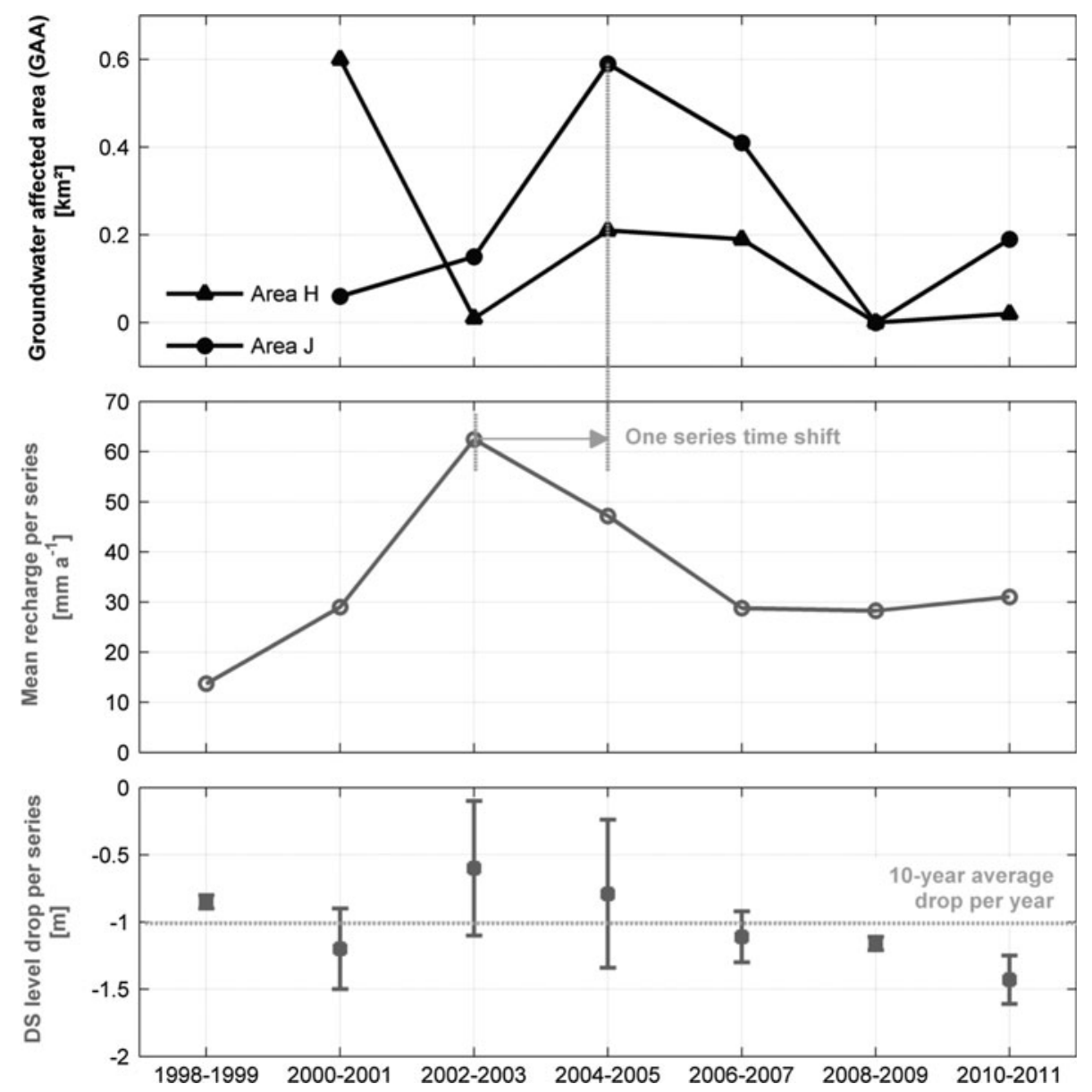

progression and the same response time-shift of one series as on the western coast. The similarity is supported by goodness-of-fit values of $d=0.67$ for area $\mathrm{H}$ and $d=0.86$ for area $\mathrm{J}$ (Appendix 4 in ESM). These numbers correspond to those derived on the western coast and indicate that the recharge-GAA relationship is applicable. Figure 9 also reveals the flushing effect to occur in the earliest series 2000-2001 for discharge area $\mathrm{H}$ due to the above average drop of the DS level of $1.5 \mathrm{~m}$. As observed on the western coast, a shift of discharge locations is also partly visible on the eastern coast at the example of discharge area J. There, the inflow varies from the tip of the Wadi Mujib fan to the north and to the south. Similar to the western coast, the hydro-geological system may change locally with the drop of the DS level establishing new flow-paths and inflow locations.

Remarks on the temporal behaviour and quantification of groundwater discharge

The congruency between curve progressions of recharge and GAA extents suggests a direct relationship. Hence, it once again confirms our hypothesis that it is possible to derive information on the temporal groundwater discharge behaviour using thermal satellite data (2013).

Following $\mathrm{Ou}$ et al. (2009), who proved a direct relationship between area of discharge plume (in the present case GAA) and discharge quantity, it appears to be possible to derive absolute volumetric quantities based upon the GAAs. However, for the present case, the authors consider the absolute quantification to be unfavourable due to the following reasons:

1. GAAs comprise discharge from terrestrial springs and an unknown discharge dimension from submarine springs and old-brine flushing.

2. Diffuse groundwater discharge with discharge $<1-5 \times$ $10^{6} \mathrm{~m}^{3} \mathrm{a}^{-1}$ as shown in Fig. 4 cannot be reliably resolved due to the coarse GSD of the satellite data.

3. The GAA delineation might miss areas induced by groundwater where the thermal contrast is insufficient or which are not directly located at the coast.

All points influence a reliable and concrete statement regarding absolute quantities. Hence, the authors suggest applying satellite data at unmonitored locations only semiquantitatively as pursued during this study. 
Our results reveal that

1. Rigid ratios of discharge volumes between different spring areas (e.g. ratio of 2:1 for Ein Feshkha 60-70 $\times$ $10^{6} \mathrm{~m}^{3} \mathrm{a}^{-1}$ to Kane/Samar $30-40 \times 10^{6} \mathrm{~m}^{3} \mathrm{a}^{-1}$ ) have to be reconsidered if discharge from submarine springs and old-brine flushing is included

2. A hydraulic change in the existing hydro-geological system as a result of the drop of the DS level likely induces changes in the discharge location.

3. The response time between recharge area and discharge locations is less than two years.

4. The so far unobserved flushing effect occurred at least during 2000-2001 and 2010-2011 along both coasts. This confirms the proposed and modelled additional water contribution of old DS-brines as a consequence of an above average DS level drop (Kiro et al. 2008; Yechieli and Sivan 2011).

\section{Conclusion}

Six potential groundwater discharge areas were identified on each coast, where general groundwater flow-paths (Mallast et al. 2011) intersect the DS coastline. All discharge areas exhibit thermal anomalies with different extents at the sea surface and hence represent groundwater discharge. This causality proves the structural control of groundwater flow in this area similar to the results of Shaban et al. (2005) in Lebanon. Based upon the abundance of thermal anomalies (termed groundwater affected areas-GAA) so far reported general spring areas could be concretised to 37 specific groundwater discharge sites along the entire coast. These sites spatially correspond to available discharge observations from field campaigns, in situ measurements or literature reports that validate our findings. Beyond that, our results provide indications for further groundwater discharge sites, spring types and discharge magnitudes along the entire coast that are so far not reported.

The temporal variability of the GAAs suggests a direct relationship to natural groundwater recharge as both display an analogous curve progression over the investigated period of 2000-2011. This proves our hypothesis that thermal satellite data are suitable to analyse discharge variability over defined time units despite the coarse GSD. It also reveals reported rigid ratios of discharge volumes between different spring areas not to be true at all times. Partially significantly different ratios exist if the total discharge (terrestrial, submarine and flushing of old brines) is considered.

Moreover, the drop of the DS level provokes a change of the hydrogeological system that leads to changes in groundwater discharge locations. During periods with above average DS level drop, an increased groundwater discharge over large areas can be observed. This is in contrast to periods with below average DS level drops during which discharge is limited to discrete locations. The increased continuous discharge is probably a consequence of the temporarily stored flushing of old brines from sediment-voids. This flushing effect matches assumptions of Yechieli and Sivan (2011) and modelling results of Kiro et al. (2008) who describe the same causality.

Although GAA and discharge quantities have a direct relationship, absolute discharge quantities cannot be reliably deduced. This is mainly due to the fact GAAs contain an unknown discharge dimension from submarine springs and old-brine flushing. A further reason applies to the coarse GSD of the satellite data set. This allows localising and assigning discharge magnitudes to larger GAAs, but groundwater discharge magnitudes $<1 \times 10^{6} \mathrm{~m}^{3} \mathrm{a}^{-1}$ can only be qualitatively localised.

Hence, from our perspective, the obtained discharge locations subsequently can be used as detailed boundary condition within groundwater modelling of this region or for further applications aiming at a sustainable groundwater management. The possibility to infer relative discharge variability might also be valuable for management concerns as it represents a cost-effective and fast method to monitor groundwater discharge behaviour over time. If it is intended to obtain absolute groundwater discharge quantities by means of remote sensing, the authors suggest using data with higher GSD, from, e.g. airborne platforms, and to parallel measure in situ groundwater discharge volumes (Danielescu et al. 2009) or to determine the discharge through mass balances (Johnson et al. 2008).

Acknowledgments The authors greatly acknowledge the grant for this study from the German Federal Ministry of Education and Research (BMBF) within the multilateral IWRM-project SUMAR (grant code: 02WM0848). We are also very grateful to the Israel Hydrological Service for the intense support and for providing spring discharge data. Further thanks are addressed to Prof. John Laronne and Yaniv Munwes (Ben Gurion University), Megilot Dead Sea, Omar Cohen and Yossi Guttman (Mekorot), and the Ein Feshkha National Park Rangers for their intense support during the course of this study. Helmholtz Impulse and Networking Fund through Helmholtz Interdisciplinary Graduate School for Environmental Research (HIGRADE) kindly supported this study. The authors are grateful to two anonymous reviewers for their helpful comments that significantly improved the manuscript.

Open Access This article is distributed under the terms of the Creative Commons Attribution License which permits any use, distribution, and reproduction in any medium, provided the original author(s) and the source are credited.

\section{References}

Akawwi E, Al-Zouabi A, Kakish M, Koehn F, Sauter M (2008) Using thermal infrared imagery (TIR) for illustrating the submarine 
groundwater discharge into the eastern shoreline of the Dead SeaJordan. Am J Environ Sci 4(6):693-700. doi:10.3844/ajessp.2008. 693.700

Al-Weshah RA (2000) The water balance of the Dead Sea: an integrated approach. Hydrol Process 14(1):145-154. doi:10. 1002/(sici)1099-1085(200001)14:1<145:aid-hyp916>3.0.co;2-n

Asmar BN, Ergenzinger P (2002) Dynamic simulation of the Dead Sea. Adv Water Resour 25(3):263-277. doi:10.1016/S03091708(01)00063-X

Barsi J, Barker JL, Schott JR (2003) An Atmospheric Correction Parameter Calculator for a single thermal band earth-sensing instrument. In: Proceedings of IGARSS 2003, Centre de Congress Pierre Bandis. Toulouse. 21-25 July 2003 doi:10.1109/ IGARSS.2003.1294665

Barsi JA, Schott JR, F.D. P, Hook SJ (2005) Validation of a webbased atmospheric correction tool for single thermal band instruments. In: Proceedings of the SPIE 5882. doi:10.1117/ 12.619990

Becker MW (2006) Potential for satellite remote sensing of ground water. Ground Water 44(2):306-318. doi:10.1111/j.1745-6584. 2005.00123.x

Ben-Avraham Z, Ten Brink U (1989) Transverse faults and segmentation of basins within the Dead Sea Rift. J Afr Earth Sci (Middle East) 8(2-4):603-616. doi:10.1016/S0899-5362(89)80047-8

Chan LH, Chung Y (1987) Barium and radium in the Dead Sea. Earth Planet Sci Lett 85(1-3):41-53

Chander G, Markham BL, Helder DL (2009) Summary of current radiometric calibration coefficients for Landsat MSS, TM, ETM + , and EO-1 ALI sensors. Remote Sens Environ 113(5): 893-903. doi:10.1016/j.rse.2009.01.007

Closson D (2005) Structural control of sinkholes and subsidence hazards along the Jordanian Dead Sea coast. Environ Geol 47:290-301. doi:10.1007/s00254-004-1155-4

Closson D, Abou Karaki N, Hallot F (2010) Landslides along the Jordanian Dead Sea coast triggered by the lake level lowering. Environ Earth Sci 59(7):1417-1430. doi:10.1007/s12665009-0128-Z

Danielescu S, MacQuarrie KTB, Faux RN (2009) The integration of thermal infrared imaging, discharge measurements and numerical simulation to quantify the relative contributions of freshwater inflows to small estuaries in Atlantic Canada. Hydrol Process 23(20):2847-2859. doi:10.1002/hyp.7383

Donlon CJ, Minnett PJ, Gentemann C, Nightingale TJ, Barton IJ, Ward B, Murray MJ (2002) Toward improved validation of satellite sea surface skin temperature measurements for climate research. J Clim 15(4):353-369. doi:10.1175/1520-0442(2002) $015<0353$ :TIVOSS $>2.0 . \mathrm{CO} ; 2$

Enzel Y, Kadan G, Eyal Y (2000) Holocene earthquakes inferred from a fan-delta sequence in the Dead Sea Graben. Quatern Res 53(1):34-48. doi:10.1006/qres.1999.2096

Feitelson E (2005) Political economy of groundwater exploitation: the Israeli case. Int J Water Resour Dev 21(3):413-423. doi: $10.1080 / 07900620500160867$

Galili U (2012) Summary of hydrometric measurements in Ein Fesh'ha during the years 2003-2011. IHS reports, vol 1/2012. Israel Hydrological Service, Jerusalem

Gardosh M, Ze Reches, Garfunkel Z (1990) Holocene tectonic deformation along the western margins of the Dead Sea. Tectonophysics 180(1):123-137. doi:10.1016/0040-1951(90)90377-k

Gräbe A, Rödiger T, Rink K, Fischer T, Sun F, Wang W, Siebert C, Kolditz O (2012) Numerical analysis of the groundwater regime in the western Dead Sea escarpment, Israel + West Bank. Environ Earth Sci 69(2) doi:10.1007/s12665-012-1795-8

Guttman Y (2000) Hydrogeology of the eastern aquifer in the Judea Hills and Jordan Valley. Multi-Lateral Project-Project 02WT9719 within the framework of the German-Israeli-
Jordanian-Palestinian Joint Research Program for the sustainable utilization of aquifer systems. Mekorot

Hact A, Gertman I (2003) Dead Sea meteorological climate. In: Nevo E, Oren A, Wasser SP (eds) Fungal life in the Dead Sea. International center for cryptogamic plants and fungi. Institute of Evolution, University of Haifa, Israel, p 361

Hadas G (2011) Ancient agricultural irrigation systems in the oasis of Ein Gedi, Dead Sea, Israel. J Arid Environ (0). doi:10.1016/ j.jaridenv.2011.08.015

IHS (2012) Spring discharge of Ein Feshkha. Qane and Samar. Israel Hydrological Service, Jerusalem

Ionescu D, Siebert C, Polerecky L, Munwes YY, Lott C, Häusler S, Bižić-Ionescu M, Quast C, Peplies J, Glöckner FO, Ramette A, Rödiger T, Dittmar T, Oren A, Geyer S, Stärk H-J, Sauter M, Licha T, Laronne JB, de Beer D (2012) Microbial and chemical characterization of underwater fresh water springs in the Dead Sea. PLoS ONE 7(6):e38319. doi:10.1371/journal.pone.0038319

Johnson AG, Glenn CR, Burnett WC, Peterson RN, Lucey PG (2008) Aerial infrared imaging reveals large nutrient-rich groundwater inputs to the ocean. Geophysical Research Letters 35(15):L15606 15601-15606. doi:10.1029/2008g1034574

Kiro Y, Yechieli Y, Lyakhovsky V, Shalev E, Starinsky A (2008) Time response of the water table and saltwater transition zone to a base level drop. Water Resour Res 44(12):W12442 1244112415. doi: $10.1029 / 2007 \mathrm{wr} 006752$

Laronne Ben-Itzhak L, Gvirtzman H (2005) Groundwater flow along and across structural folding: an example from the Judean Desert, Israel. J Hydrol 312(1-4):51-69. doi:10.1016/j.jhydrol. 2005.02.009

Lensky NG, Dvorkin Y, Lyakhovsky V, Gertman I, Gavrieli I (2005) Water, salt, and energy balances of the Dead Sea. Water Resour Res 41(12):W12418. doi:10.1029/2005wr004084

Magal E, Weisbrod N, Yakirevich A, Kurtzman D, Yechieli Y (2010) Line-source multi-tracer test for assessing high groundwater velocity. Ground Water 48(6):892-897. doi:10.1111/j.17456584.2010.00707.x

Mallast U, Gloaguen R, Geyer S, Rödiger T, Siebert C (2011) Derivation of groundwater flow-paths based on semi-automatic extraction of lineaments from remote sensing data. Hydrol Earth Syst Sci 15(8):2665-2678. doi:10.5194/hess-15-2665-2011

Mallast U, Siebert C, Gloaguen R, Friesen J, Rödiger T, Geyer S, Merz R (2013) How to identify groundwater caused thermal anomalies in lakes based on long-term medium resolution images in semi-arid regions. Hydrological Earth System Sciences (HESS) (submitted)

McFeeters SK (1996) The use of the normalized difference water index (NDWI) in the delineation of open water features. Int $\mathrm{J}$ Remote Sens 17(7):1425-1432. doi:10.1080/0143116960894 8714

Mejías M, Ballesteros BJ, Antón-Pacheco C, Domínguez JA, GarciaOrellana J, Garcia-Solsona E, Masqué P (2012) Methodological study of submarine groundwater discharge from a karstic aquifer in the Western Mediterranean Sea. J Hydrol 464-465:27-40. doi: 10.1016/j.jhydrol.2012.06.020

Munwes Y, Laronne JB, Geyer S, Siebert C, Sauter M, Licha T (2010) Direct measurement of submarine groundwater spring discharge upwelling into the Dead Sea. In: IWRM, Karlsruhe, 24-25. November 2010

Ou S, Zhang H, Wang D-x (2009) Dynamics of the buoyant plume off the Pearl River Estuary in summer. Environ Fluid Mech 9(5):471-492. doi:10.1007/s10652-009-9146-3

Rimawi O, Salameh E (1988) Hydrochemistry and groundwater system of the Zerka Ma'in-Zara thermal field, Jordan. J Hydrol 98(1-2):147-163. doi:10.1016/0022-1694(88)90211-9

Roseen RM (2002) Quantifying groundwater discharge using thermal imagery and conventional groundwater exploration techniques 
for estimating the nitrogen loading to a meso-scale inland estuary. PhD Thesis, University of New Hampshire, New Hampshire

Salameh E (1996) Water quality degradation in Jordan (impacts on environment, economy and future generations resources base). Friedrich Ebert Stiftung, Royal Society for the Conservation of Nature, Amman

Salameh E, Bannayan H (1994) Water Resources of Jordan-Present Status and Future Potentials. Friedrich Ebert Stiftung Amman

Salameh E, El-Naser H (1999) Does the actual drop in Dead Sea level reflect the development of water sources within its drainage basin? Acta Hydrochim Hydrobiol 27(1):5-11. doi:10.1002/ (sici) 1521-401x(199901)27:1<5:aid-aheh5>3.0.co;2-z

Salameh E, Hammouri R (2008) Sources of groundwater salinity along the flow path, Disi-Dead Sea/Jordan. Environ Geol 55(5):1039-1053. doi:10.1007/s00254-007-1053-7

Schulz S, Siebert C, Rödiger T, Al-Raggad M, Merz R (2013) Application of the water balance model J2000 in a semi-arid environment to estimate groundwater recharge-a case study in the Zarqa River catchment, NW-Jordan. Environ Earth Sci 69(2)

Shaban A, Khawalie M, Abdallah C, Faour G (2005) Geologic controls of submarine groundwater discharge: application of remote sensing to north Lebanon. Environ Geol 47. doi:10.1007/ s00254-004-1172-3

Shalev E, Lyakhovsky V, Yechieli Y (2007) Is advective heat transport significant at the Dead Sea basin? Geofluids 7(3): 292-300. doi:10.1111/j.1468-8123.2007.00190.x

Shalev E, Shaliv G, Yechieli Y (2009) Hydrogeology of the Southern Dead Sea Basin (the area of the evaporation ponds of the Dead Sea Works). Report GSI, vol 25. Geological Survey of Israel, Jerusalem

Siebert C, Rödiger T, Geyer S, Mallast U, Gräbe A (2011) Western Dead Sea spring measurements. unpublished data

Stanhill G (1990) Changes in the surface temperature of the Dead sea and its heat storage. Int J Climatol 10(5):519-536. doi:10.1002/ joc. 3370100508
Stiller M, Chung YC (1984) Radium in the Dead Sea: a possible tracer for the duration of meromixis. Limnol Oceanogr 29(3):574-586

Torgerson CE, Faux RN, McIntosh BA, Poage NJ, Norton DJ (2001) Airborne thermal remote sensing for water temperature assessment in rivers and streams. Remote Sens Environ 76:386-398. doi:10.1016/S0034-4257(01)00186-9

USGS (2011) Landsat ETM + product description from the earth resources observation and science (EROS) Center. http:// eros.usgs.gov/\#/Find_Data/Products_and_Data_Available/ETM. Accessed 17 Nov 2011

USGS (2012) USGS Homepage-Landsat Mission (SLC-off Products: Background), http://landsat.usgs.gov/products_slcoffback ground.php. Accessed 14 Aug 2012

Vengosh A, Starinsky A, Kolodny Y, Chivas AR (1991) Boron isotope geochemistry as a tracer for the evolution of brines and associated hot springs from the Dead Sea, Israel. Geochimica et Cosmochimica Acta 55(6):1689-1695. doi:10.1016/00167037(91)90139-v

Wenyao L, Field R, Gantt R, Klemas V (1987) Measurement of the surface emissivity of turbid waters. Chin J Oceanol Limnol 5(4):363-369. doi:10.1007/bf02843818

Willmott CJ (1981) On the validation of models. Phys Geogr 2:184-194

Wloczyk C, Richter R, Borg E, Neubert W (2006) Sea and lake surface temperature retrieval from Landsat thermal data in Northern Germany. Int J Remote Sens 27(12):2489-2502. doi: 10.1080/01431160500300206

Yechieli Y, Sivan O (2011) The distribution of saline groundwater and its relation to the hydraulic conditions of aquifers and aquitards: examples from Israel. Hydrogeol J 19(1):71-81. doi: 10.1007/s10040-010-0646-5

Yechieli Y, Shalev E, Wollman S, Kiro Y, Kafri U (2010) Response of the Mediterranean and Dead Sea coastal aquifers to sea level variations. Water Resour Res 46(12):W12550 12551-12511. doi:10.1029/2009wr008708 